\title{
An Integrated Drive for Two PMSMs Involved Automotive Applications and Development of Current Reference Expanded Two Arm Modulation Technique
}

\author{
V. Krishnakumar ${ }^{1}$, V. Kamaraj ${ }^{2}$, C. Adrien Perianayagam ${ }^{3}$ \\ ${ }^{1}$ Research Scholar, Department of EEE, SSN College of Engineering, Chennai, India \\ ${ }^{2}$ Department of Electrical and Electronics Engineering, SSN College of Engineering, Chennai, India \\ ${ }^{3}$ Department of Electrical and Electronics Engineering, Sri Manakula Vinayagar Engineering College, \\ Pondicherry, India \\ Email:v_krishnakumar@ymail.com,kamarajv@ssn.edu.in
}

Received 1 April 2016; accepted 25 April 2016; published 20 June 2016

Copyright (C) 2016 by authors and Scientific Research Publishing Inc.

This work is licensed under the Creative Commons Attribution International License (CC BY). http://creativecommons.org/licenses/by/4.0/

(c) (i) Open Access

\section{Abstract}

A five leg inverter (FLI) control is incorporated to drive two independent rated permanent magnet synchronous motors (PMSMs) for automotive applications. Literature evidences many attempts of employing the FLI for controlling two general purpose/special motors, where variety of modulation techniques has been practiced for performance enhancement. Also in these cases one leg of inverter is common to both the motors. The expanded two arm modulation (ETAM) has been generally engaged in FLI. In ETAM the percentage voltage utilization factor (VUF) is calculated based on " $\alpha_{\max }$ ", where " $\alpha_{\max }$ " is the maximum modulation index and equal to $1 / \sqrt{3}$ and hence it restricts the VUF to $50 \%$. This makes the FLI drives to use the dc link in inefficient way, which is due to the fact that conventional ETAM works with voltage reference. This paper modifies the ETAM in an ingenious way to improve the VUF further through current reference. In addition, the developed current reference expanded two arm modulation (CRETAM) minimizes the current harmonics and torque ripple as well. A detailed comparison of the CRETAM with the conventional ETAM and the competent digital counterpart, space vector pulse width modulation (SVPWM), is also presented. The enhancement in VUF, torque ripple minimization and current total harmonic distortion (THD) reduction are found in the MATLAB based simulation results.

\section{Keywords}

EV/HEV Traction Drive, SVPWM, Five Leg Inverter, Two Permanent Magnet Synchronous Motor

How to cite this paper: Krishnakumar, V., Kamaraj, V. and Adrien Perianayagam, C. (2016) An Integrated Drive for Two PMSMs Involved Automotive Applications and Development of Current Reference Expanded Two Arm Modulation Technique. Circuits and Systems, 7, 1794-1815. http://dx.doi.org/10.4236/cs.2016.78155 


\section{Drive, Current Reference Expanded Two Arm Modulation (CRETAM), Expanded Two Arm} Modulation (ETAM)

\section{Introduction}

With the increasing demand for environmentally friendlier and higher fuel economy, the vehicle automotive industries have started to focus on electric vehicles, hybrid electric vehicles (HEVs), plug-in hybrid electric vehicles (PHEVs) and fuel cell vehicles. In electric vehicles, the challenge is to achieve high efficiency, ruggedness, small sizes and also low cost power converters and electric machines as well as in associated electronics [1]. In such systems, electric motor and associated drives circuits may take major space and also high budget. These drive systems need to possess high torque density and power density with very wide speed range (low speed crawling to high speed cruising) and good dynamic performance [2]-[4]. With the advent of high-energy permanent-magnet (PM) materials such as neodymium-iron-born (Nd-Fe-B), Samarium-cobalt (Sm-Co) etc., the development of PM motor drives has created an accelerated pace in automotive industries [5] [6]. In the dynasty of PM motors, the permanent magnet synchronous motors (PMSMs) have some merits such as higher efficiency, less weight, low vibration and acoustic noise, easiness in system design etc. In EVs and some HEVs, two major electric drives are necessary: a traction drive to deliver the driving force for the vehicle and a compressor drive for the air-conditioning or climate control system [heating, ventilating and air conditioning-high voltage AC (HVAC) system] [7]. This enables the controller to adjust the cooling or heating power without depending on the internal combustion engine (ICE). Normally, the traction drive is rated at a relatively high power level and required to provide fast dynamic response and high efficiency. The HVAC compressor drive, on the other hand, is rated at a much lower power level (a few kilowatts) and also high dynamic performances are not required.

Traditionally, two separate drives, each employing a separate three phase voltage source inverter (VSI), are being used to gain independent control as shown in Figure 1. Even though for an automotive application, cost and reliability are two major concerns, but small size volume, light weight and high efficiency are also important [8]. Inverter is designed with fewer components with similar or even reduced performances and therefore desirable in automotive application which can be achieved by five leg inverter (FLI) as shown in Figure 1.

A multiple current-regulated pulse width modulated VSI (PWM-VSI) based dual two phase PWM inverter (B4 topology) has been proposed [9], which utilizes eight switches to produce two sets of $3 \varphi$ or $2 \varphi$ sinusoidal output currents. It results in reduced switch count, minimized dc link current, and thus reduces overall losses, cost and weight of the drive. A modified, simple control method has been applied to multi-leg voltage source converter used to supply balanced and unbalanced load [10]. The above concept is obsolete and failed to provide required drive performance in terms of line current total harmonic distortion (THD), torque ripple etc. A sev-

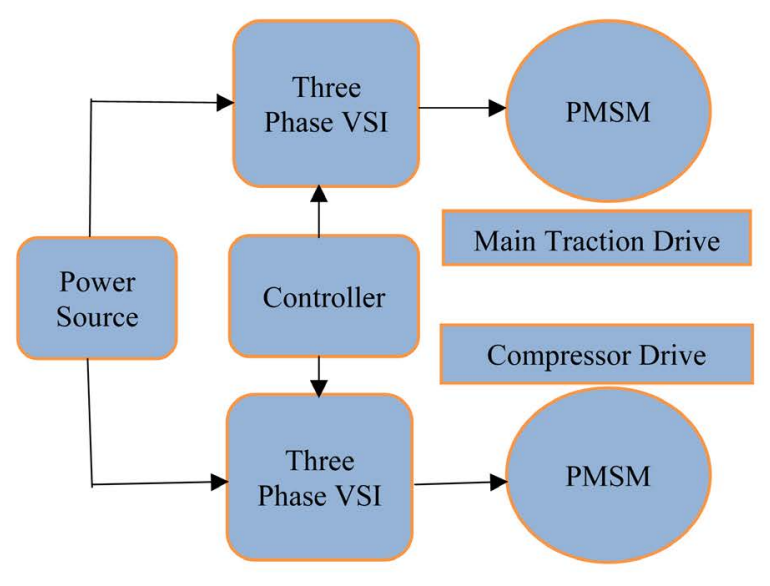

(a)

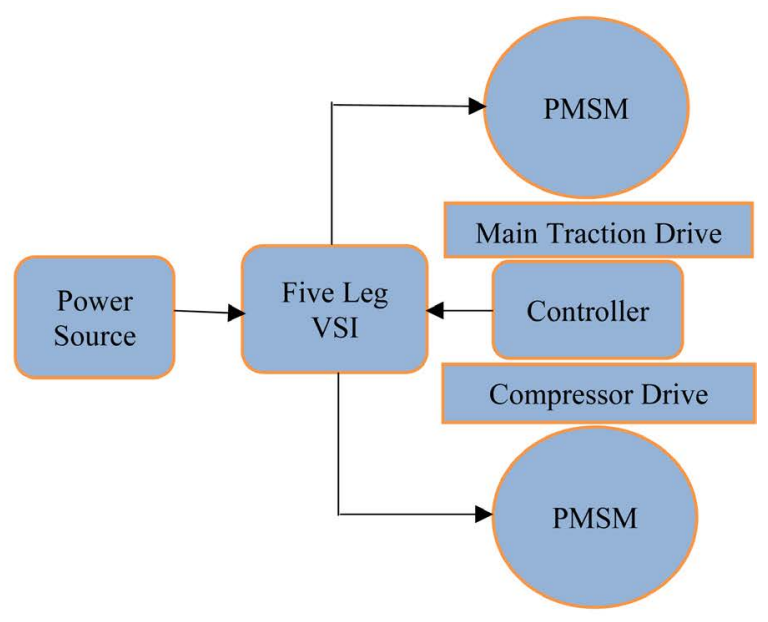

(b)

Figure 1. Two motor drives options (a) Three Leg VSI (b) FLI. 
en-phase indirect rotor flux oriented control (RFOC) has been developed and discussed with the examination of speed and torque modes [11]. An integrated inverter, built-in to drive traction motor and compressor motor, has been used for speed control, which also reduces the compressor drive cost in HEV/EV applications [12]. A six-phase two motors drive has been often developed to work on the principle of indirect vector control to ensure the current control in stationary reference frame [13]. This technique uses mathematical modeling of system and the function is based on a set of d-q equations. It increases the stator winding losses in the series connected motor drive. In EHV/HV applications, it often requires to control two or more motors. The first intent has been reducing the installation cost of converter topology, which minimizes the power semiconductor switch count. The second intent has been devising a suitable PWM technique for the multimotor drive [14] [15].

Various PWM techniques have been reported in the literature, they are dual voltage modulation (DVM), modulation block method (MBM), inversion table method (IVM) and double zero-sequence injection method (DZM) [16]. Among these methods, the best performance has been achieved by DZM method, which improves dc bus utilization and reduces the current ripple. Further in the study, the computation of voltage utilization factor (VUF) has not been described for the DZM method. Later the expanded two arm modulation control (ETAM) has been proposed in order to improve the VUF [17] [18]. In this method, the load is independently controlled with two drive motors. VUF for conventional ETAM is $50 \%$, while it is $86.6 \%$ when third harmonic wave is added in reference. But addition of the harmonic component in the reference function causes the poor harmonic profile. A modulation method, which treats the VUF of two motors separately and results effective utilization of dc link voltage, has been devised when the motor is operated in constant power region [19]-[21]. The other modified modulation technique has been presented to lower the dc link voltage [22], where the two motors are connected in wye (Y) and delta (D) arrangements respectively by C. B. Jacobina et al. They developed the motor model and a PWM strategy for YD-Parallel, DD-parallel and YD-series, which showed the flexibility of the system.

More recently, the closed loop integrated dual ac drive is used to control two PM motors, which has the merit of neglecting extra copper loss in the main motor caused by the auxiliary motor current, has been proposed [23]. The space vector PWM (SVPWM) has been implemented to FLI based independent control of two PMSM [24]. The references of both machines became vectors in the respective d-q planes with completely arbitrary reference, positioned in any of the six sectors of the planes. The zero vectors are equally shared to operate in standard (continuous) modulation. Recent implementations have used the sampled amplitude of reference phase voltages to realize the simple SVPWM method [25], where the computation time has been reduced as it does not involve in any sector identification.

Though the earlier schemes of FLI driven two motors control targeted the performance enhancements such as VUF, switch count, overall losses and magnitude of dc link current, these schemes need to be further improved in terms of THD, torque ripple minimization, VUF etc. This paper presents a current reference expanded two arm modulation (CRETAM) technique to control the two differently rated PMSMs. The performance of the proposed CRETAM is compared with the SVPWM and ETAM schemes.

\section{Five Leg Inverter Drive for Double PMSM}

The power circuit of FLI which consists of five legs, each leg consists of pair of power switching device (MOSFET) with anti-parallel diode, is shown in Figure 2. The third (C) phases of both the motor switch connected to one common leg where other two phases of them are attached with separate set of arms.

The switching function and the restriction condition can be described by the following equation.

Switch on: $S_{m a}=1$

Switch off: $S_{m a}=0$

Restricted Function $=S_{m 1}+S_{m 2}=1$

where, $m \varepsilon\{1,2,3,4$, and 5$\}$ is the number of legs and $a \varepsilon\{1,2\}$ is the number of arms.

It is worth noting that even though the FLI is an integrated drive for double PMSM arrangement, it is always possible to control the motors independently with different set points, speed control schemes, dynamic performance requirements, frames of control schemer etc. The drive can be operated in various conditions such as,

- Reference speed commands of main and auxiliary PMSM drives are different.

- Loads torque commands of main and auxiliary PMSM drive are different.

- Rated specification and parameters of two motors are different etc. 


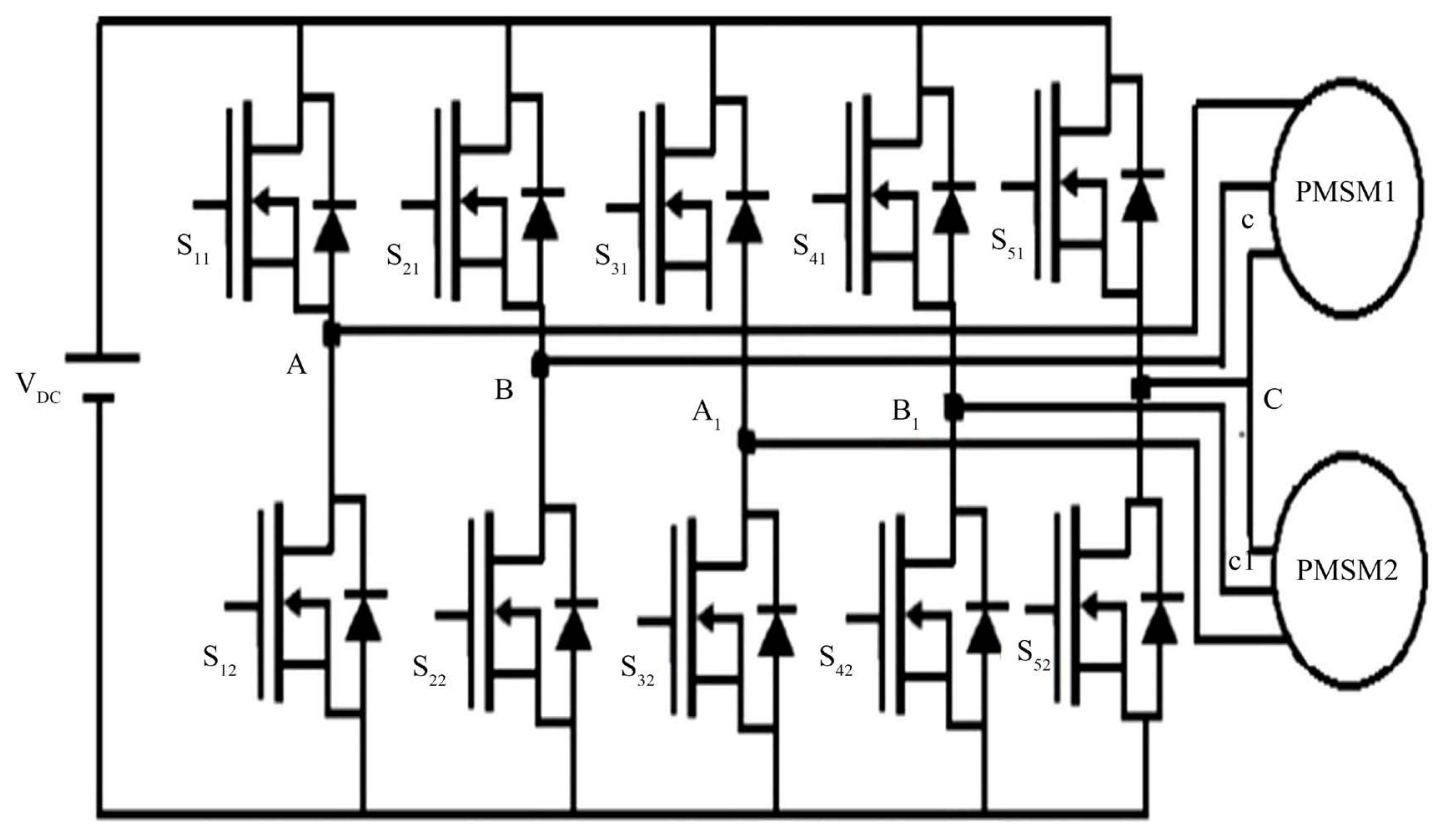

Figure 2. Structure of five leg VSI.

Usually when two motors are driven with two individual three-leg inverters, there are twelve power switching devices are needed. A two motor drive supplied using the FLI topology offers a saving of two switches. The size, gate drive requirement and control complexity of the inverter are therefore reduced. All of these features lead to a potential reduction in capital cost when compared with standard dual three phase inverter approach. Driving two motors independently, the amplitude of the peak current flow in common leg can be up to twice of others, hence its design must be taken care of appropriate rating. This makes the drive to lose its modularity in terms leg interchangeability.

\section{PWM Modulation Methods for FLI}

The conventional PWM techniques applicable to the three phase VSI cannot be used for the FLI in the independent drive mode. The state-of-the-art PWM techniques of the FLI, applicable when two motors are controlled, are as follows.

1) ETAM.

2) Voltage reference based Space Vector Approach.

\subsection{Expanded Two Arm Modulation Method}

It is possible to independently control the two PMSMs (which are the main traction motor and the auxiliary compressor motor) by providing different commands to each motor with the help of ETAM. ETAM is basically a natural sampled sine PWM (SPWM) logically extended for FLI. This extension inherits two important features viz. synchronization of reference functions and decoupling between two sets of reference functions. The decoupling between the references function of main drive and auxiliary drive legs make them to work independently.

The foremost step in ETAM is synthesizing the reference functions which are ingenious/decoupled combination of phase voltages. Each drive manipulates two reference voltages by assuming the third phase as common as indicated in Figure 3 (hence four reference functions). It is to remember that in a typical line voltage synthesizing procedure of conventional three-phase system gives equal opportunity for all the phase voltages. The phase and line voltages formation in the conventional three-phase system and the one phase suppression scheme involved in the ETAM are detailed in Figure 4(a) and Figure 4(b) respectively. The fifth reference function (for $\mathrm{C}$ phase) is theoretically zero while the zero reference function will keep the switches of $\mathrm{C}$ leg remain OFF state. Hence, practical implementation a function called $V_{c m i n}$ is added. To keep the inter-relations among the reference functions, this $V_{c m i n}$ is added with all the reference functions. 


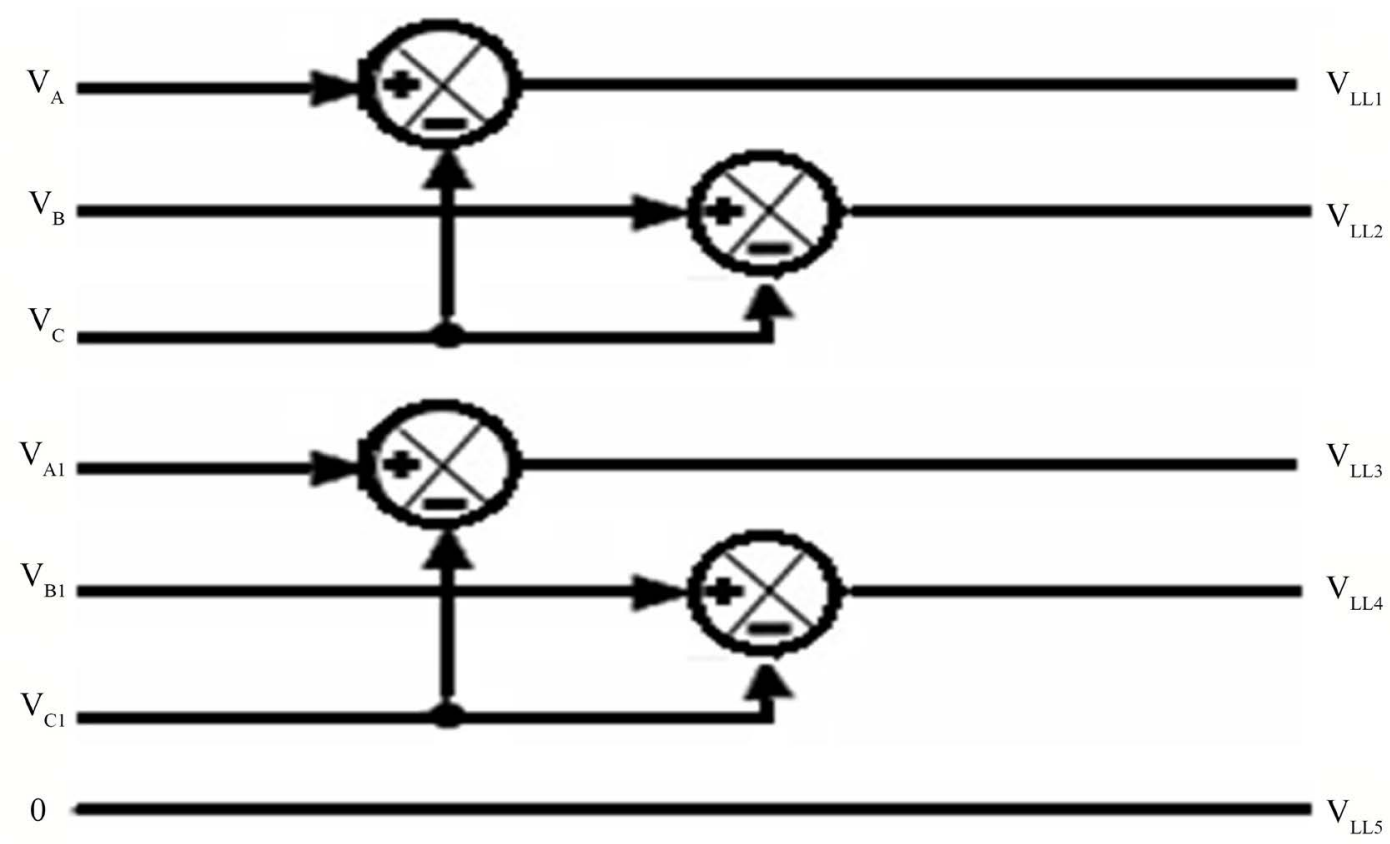

Figure 3. Generation of reference functions of ETAM.
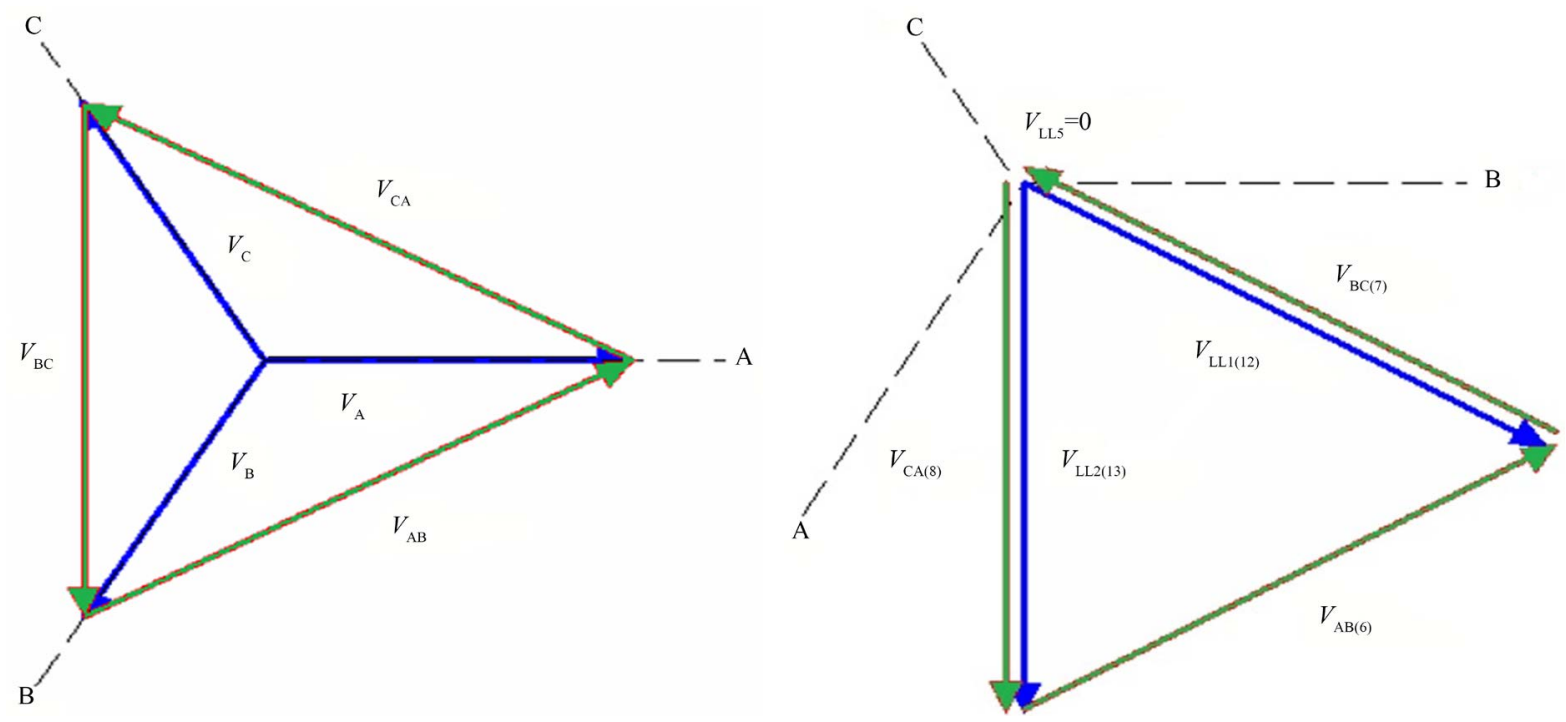

Figure 4. Formulation of line voltages from phase voltages.

The voltage commands (reference functions) of individual leg are calculated as follows.

$$
\begin{gathered}
V_{L L 1}=V_{A}-V_{C} \\
V_{L L 2}=V_{B}-V_{C} \\
V_{L L 3}=V_{A 1}-V_{C 1} \\
V_{L L 4}=V_{B 1}-V_{C 1} \\
V_{L L 5}=V_{C}-V_{C}=V_{C 1}-V_{C 1}=0
\end{gathered}
$$

where, $V_{L L m}$ is the voltage command of $\mathrm{m}^{\text {th }}$ leg. $m=\{1,2,3,4,5\} ; V_{A}, V_{B}, V_{C}, V_{A 1}, V_{B 1}$, and $V_{C 1}$ are the phase voltage commands (references involved in two VSI based drive system). The common rule in the natural sampled 
PWM scheme is the expected (terminal) voltage must be the reference function or at least it must be the function expected voltage. The reference functions described in (1) to (5) are just functions derived from fictions dual three-phase supply system. Those reference functions can always be related with the output voltage command as follows.

$$
\begin{aligned}
& V_{A B}^{*}=V_{L L 1}-V_{L L 2}=V_{A}-V_{B} \\
& V_{B C}^{*}=V_{L L 2}-V_{L L 5}=V_{B}-V_{C} \\
& V_{C A}^{*}=V_{L L 5}-V_{L L 1}=V_{C}-V_{A} \\
& V_{A 1 B 1}^{*}=V_{L L 3}-V_{L L 4}=V_{A 1}-V_{B 1} \\
& V_{B 1 C 1}^{*}=V_{L L 4}-V_{L L 5}=V_{B 1}-V_{C 1} \\
& V_{C 1 A 1}^{*}=V_{L L 5}-V_{L L 3}=V_{C 1}-V_{A 1}
\end{aligned}
$$

Equations (6) to (11) are for just validation purpose while the functional references are obtained by adding $V_{c m i n}$ with them.

$$
\begin{gathered}
V_{L L 1}=V_{A}-V_{C}+V_{c m i n} \\
V_{L L 2}=V_{B}-V_{C}+V_{c m i n} \\
V_{L L 3}=V_{A 1}-V_{C 1}+V_{c m i n} \\
V_{L L 4}=V_{B 1}-V_{C 1}+V_{c m i n} \\
V_{L L 5}=0+V_{c m i n}
\end{gathered}
$$

The references from (12) to (16) can be used with regular carrier for generating the gating pulses.

\subsection{Space Vector Approach}

The digital PWM approach called, SVPWM, is extended to FLI as well. The idea is involving two three phase SVPWM modulators to control two PMSMs independently. Using space vector principle, the decoupled reference functions can be obtained for each PMSM in synchronously rotating frame, the d-q axis. For any arbitrary position of the reference vector, apposite two active vectors are chosen from the six vector group. The generated output from SV modulators are restructured to obtain the duty cycle $\delta$ over the total switching period. Adopting both modulators in the standard manner to operate for application under equally shared total timing between zero vectors 000 and 111, and each reference vector will be realized on average over the switching period by means of two adjacent active vectors. Figure 5 represents the outline of SVPWM strategy applicable to FLI.

In a similar way as in case of ETAM, a simple summing of the duty cycles $(\delta)$ generated from each modulator can be used to determine the culminating (five) duty cycles for the FLI.

$$
\begin{aligned}
& \delta_{A}=\delta_{a 1}+\delta_{c 2} ; \\
& \delta_{B}=\delta_{b 1}+\delta_{c 2} ; \\
& \delta_{C}=\delta_{c 1}+\delta_{c 2} ; \\
& \delta_{D}=\delta_{a 2}+\delta_{c 1} ; \\
& \delta_{E}=\delta_{b 2}+\delta_{c 1} ;
\end{aligned}
$$

The first three relations of equation of (17), duty cycle, $\delta_{c 2}$ is added to all the three duty cycles of modulator 1 , while $\delta_{c 1}$ is added to outcomes of modulator 2 .

In case of two three phase VSIs, Figure 6(a) depicts the switching pattern generated for inverter 1 and (b) depicts the switching pattern generated for inverter 2 for permissible set of modulation indices. By combining these patterns the pattern for FLI is achieved as pictured in Figure 6(c).

Thus the individual SVPWM signals are generated for each PMSM drive and the modulator is able to satisfy the needs of both main and auxiliary PMSMs simultaneously. 


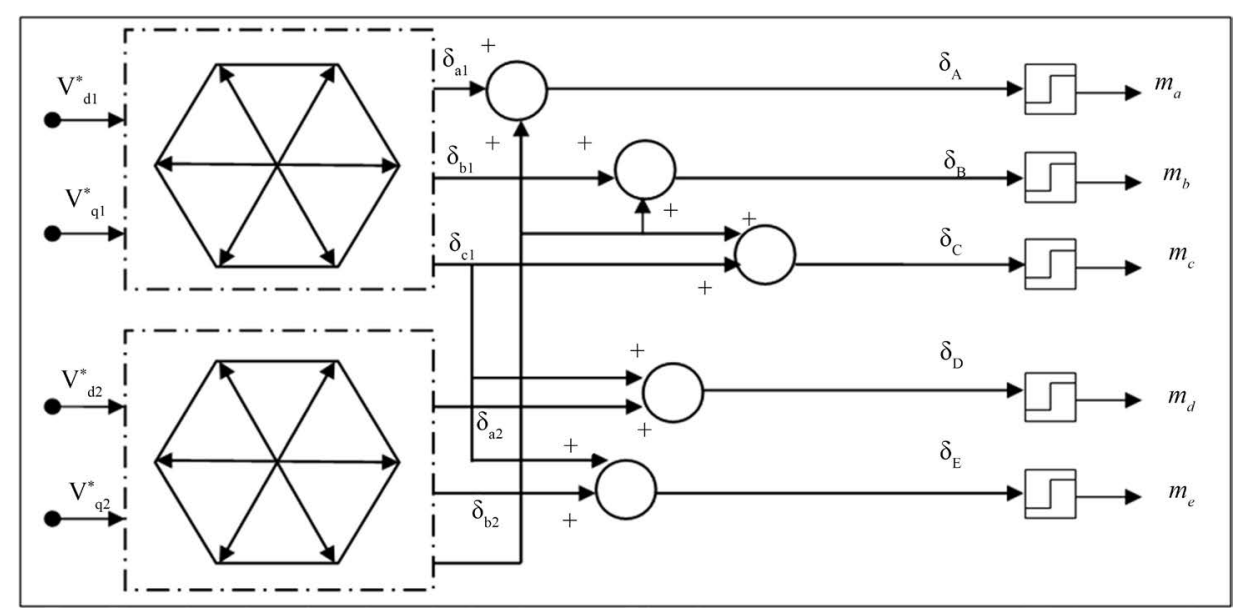

Figure 5. Extension of SVPWM to FLI.

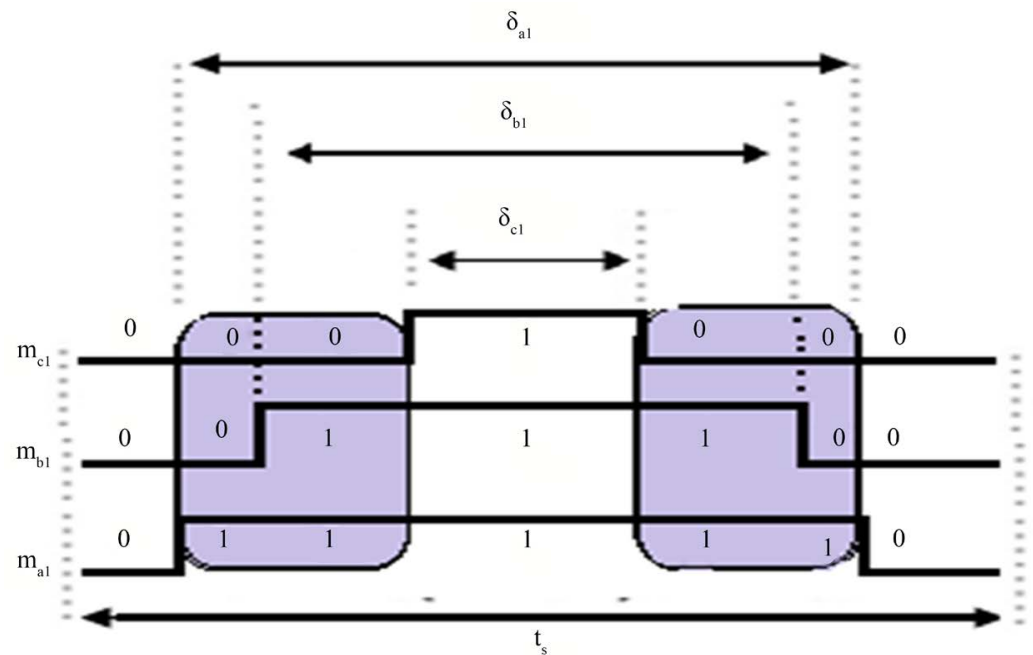

(a)

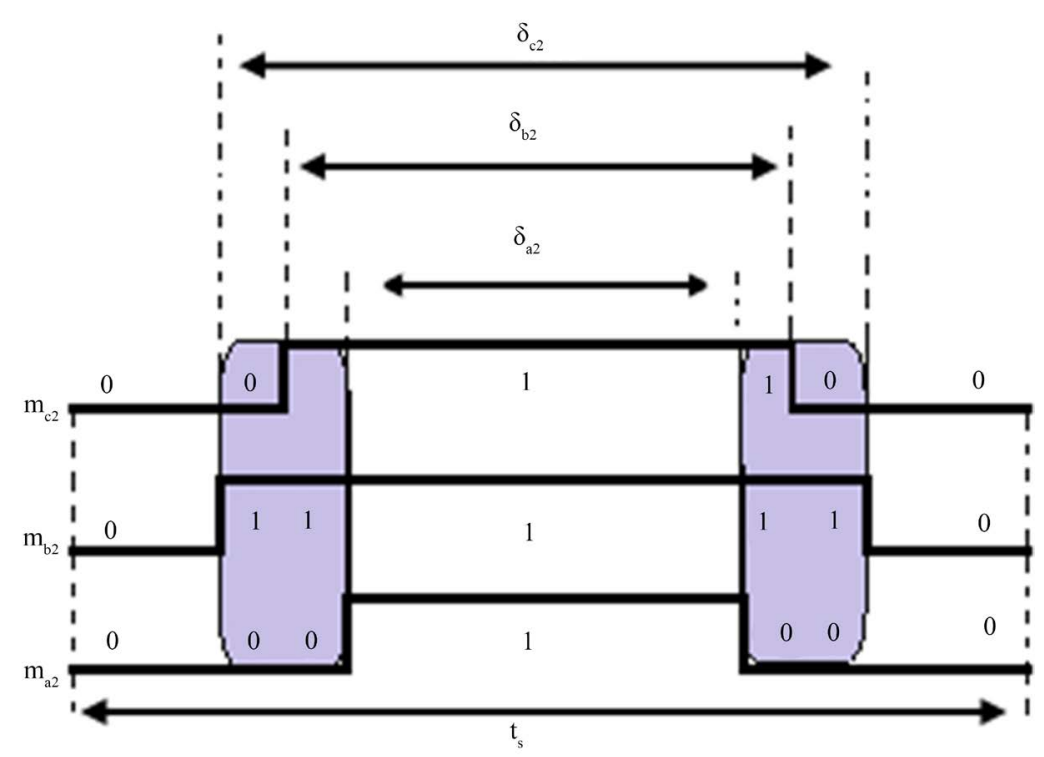

(b) 


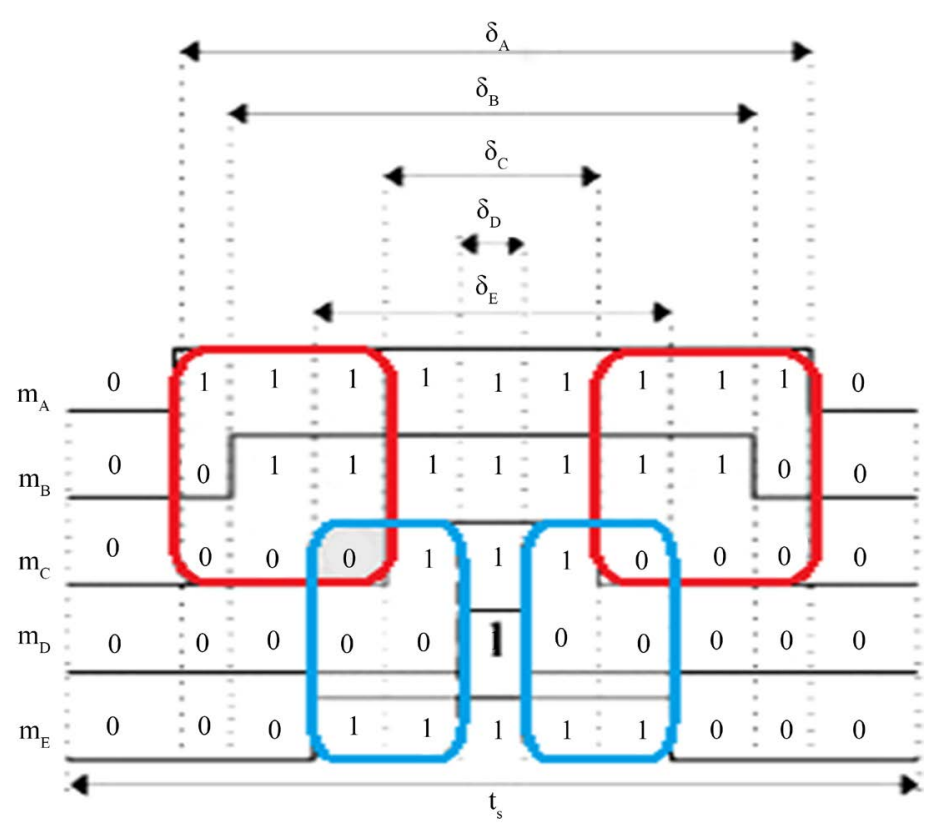

(c)

Figure 6. Arriving the switching pattern of FLI-SVPWM. (a) Switching pattern for three phase inverter 1. (b) Switching pattern for three phase inverter 2. (c) Switching pattern applicable to FLI.

\section{Proposed PWM Strategy}

An ingenious PWM technique for FLI to command each motor is suggested in this section. The proposed current reference expanded two arm modulation (CRETAM), is similar to hysteresis control, and requires actual current and reference current signals to generate the pulse pattern. The crux of the CRETAM is schemed in Figure 7.

In the CRETAM, current references are given by the equations.

$$
\begin{aligned}
I_{e a} & =i_{a r}-i_{a} \\
I_{e b} & =i_{b r}-i_{b} \\
I_{e c} & =i_{c r}-i_{c} \\
I_{e a 1} & =i_{a r 1}-i_{a 1} \\
I_{e b 1} & =i_{b r 1}-i_{b 1} \\
I_{e c 1} & =i_{c r 1}-i_{c 1}
\end{aligned}
$$

where, $i_{a}, i_{b}$ and $i_{c}$ are the actual currents of motor $1 . i_{a r}, i_{b r}$, and $i_{c r}$ are the reference currents of motor 1 . Similarly, $i_{a 1}, i_{b 1}$ and $i_{c 1}$ are the actual currents of motor 2 and $i_{a r 1}, i_{b r 1}$ and $i_{c r 1}$ are the reference currents of motor 2.

$$
\begin{gathered}
I_{L 1}=I_{e a}-I_{e c}=i_{a}-i_{c} \\
I_{L 2}=I_{e b}-I_{e c}=i_{b}-i_{c} \\
I_{L 3}=I_{e c}-I_{e c}=0 \\
I_{L 4}=I_{e a 1}-I_{e c 1}=-i_{a 1}-i_{c 1} \\
I_{L 5}=I_{e b 1}-I_{e c 1}=-i_{b 1}-i_{c 1}
\end{gathered}
$$

$I_{e a}, I_{e b}$ and $I_{e c}$ are the current errors of motor 1 and $I_{e a 1}, I_{e b 1}$ and $I_{e c 1}$ are the current errors of motor2. $I_{L 1}, I_{L 2}, I_{L 3}$, $I_{L 4}$ and $I_{L 5}$ are the current references which are compared with triangular carrier signals to generate the pulses of 


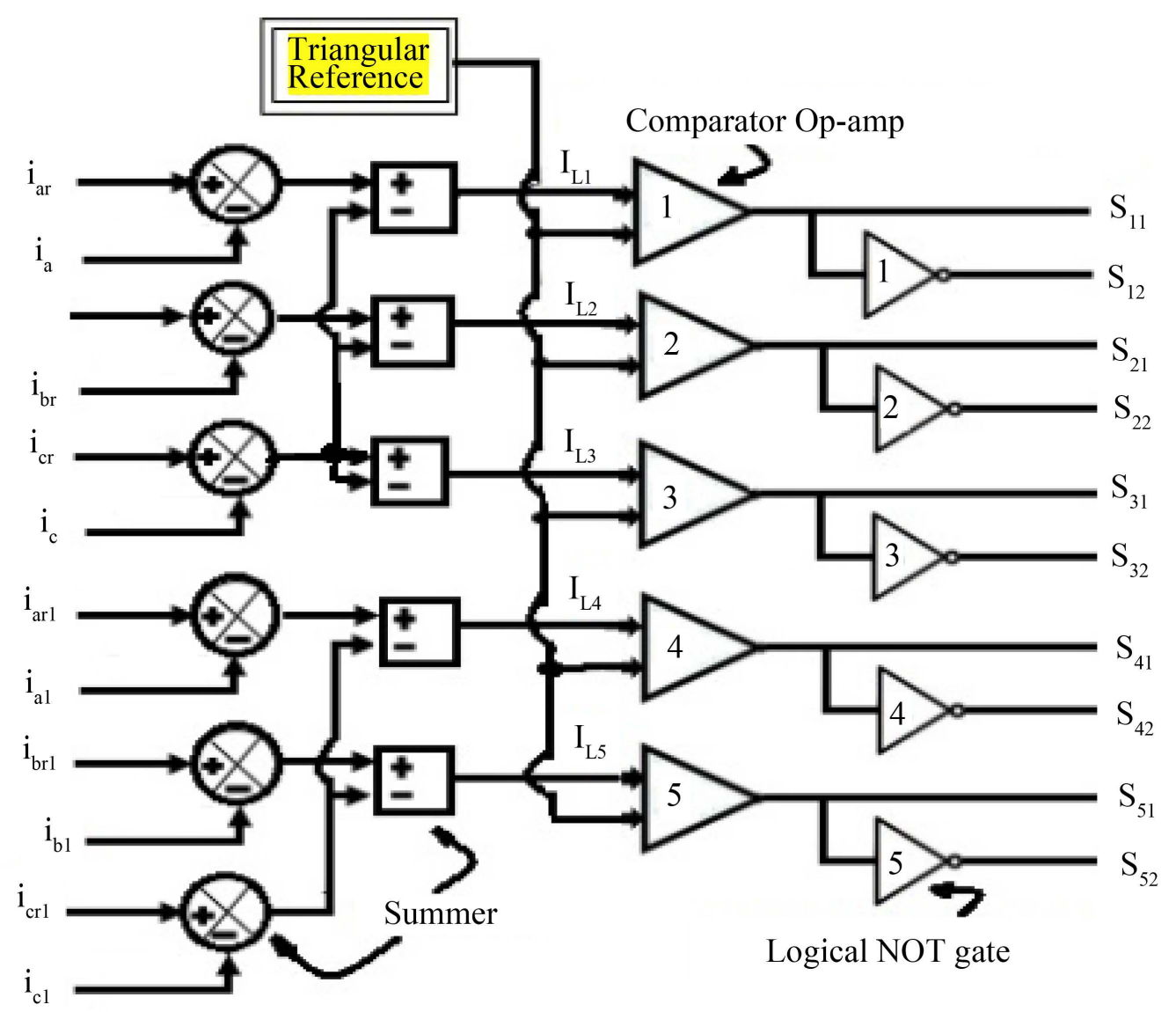

Figure 7. Proposed CRETAM.

FLI. The CRETAM paves to reduction in both torque ripple and THD, and enhancement in VUF.

\subsection{PMSM Machine Model}

The dynamic model of the PMSM is derived in synchronously rotating frame (dq axes). The stator dq axes' voltage equations of the PMSM in the rotor reference frame are

$$
\begin{gathered}
V_{q}=R i_{q}+p \lambda_{q}+\omega_{s} \lambda_{d} \\
V_{d}=R i_{d}+p \lambda_{d}-\omega_{s} \lambda_{q}
\end{gathered}
$$

where, $\lambda_{q}=L_{q} i_{q}$ and $\lambda_{d}=L_{d} i_{d}+\lambda_{a f} ; V_{d}$ and $V_{q}$ are the dq axis voltages; $i_{d}$ and $i_{q}$ are the dq axes stator currents; $L_{d}$ and $L_{q}$ are the dq axes inductances; $\lambda_{d}$ and $\lambda_{q}$ are the dq axes stator flux linkages; $R$ and $\omega_{s}$ are the stator resistance and synchronous (angular) frequency. $\lambda_{a f}$ is the stator flux linkage due to the rotor magnets.

The electromagnetic torque is given by

$$
T_{e}=3 P\left[\lambda_{a f} i_{q}+\left(L_{d}-L_{q}\right) i_{d} i_{q}\right]
$$

And the equation for the motor dynamics is

$$
T_{e}=T_{L}+B \omega_{r}+J p \omega_{r}
$$

" $p$ " is the number of pole pairs; $T_{L}$ is the load torque; $B$ is the damping coefficient; $\omega_{r}$ is the rotor speed and $J$ is the moment of inertia.

$$
\omega_{r}=p \theta_{r}
$$

For dynamic simulation, the equation of the PMSM presented in (29)-(33) must be expressed instate space 
form as shown between (34) and (38).

$$
\begin{gathered}
p i_{d}=\left(V_{d}-R i_{d}+\omega_{s} L_{d} i_{q}\right) / L_{d} \\
p i_{q}=\left(V_{q}-R i_{q}+\omega_{s} L_{d} i_{d}-\omega_{s} \lambda_{a f}\right) / L_{d} \\
p \omega_{r}=\left(T_{e}-T_{L}-B \omega_{r}\right) / J
\end{gathered}
$$

The dq variables are obtained from $\mathrm{a}, \mathrm{b}, \mathrm{c}$ variables through the park transform defined below:

$$
\left[\begin{array}{l}
V_{d} \\
V_{q} \\
V_{0}
\end{array}\right]=\frac{2}{3}\left[\begin{array}{ccc}
\cos (\theta) & \cos \left(\theta-\frac{2 \pi}{3}\right) & \cos \left(\theta+\frac{2 \pi}{3}\right) \\
\sin (\theta) & \sin \left(\theta-\frac{2 \pi}{3}\right) & \sin \left(\theta+\frac{2 \pi}{3}\right) \\
\frac{1}{2} & \frac{1}{2} & \frac{1}{2}
\end{array}\right]\left[\begin{array}{l}
V_{a} \\
V_{b} \\
V_{c}
\end{array}\right]
$$

The $\mathrm{a}, \mathrm{b}, \mathrm{c}$ variables are obtained from the $\mathrm{d}$, q variables through the inverse park transform defined below:

$$
\left[\begin{array}{l}
V_{a} \\
V_{b} \\
V_{c}
\end{array}\right]=\frac{2}{3}\left[\begin{array}{ccc}
\cos (\theta) & \sin (\theta) & 1 \\
\cos \left(\theta-\frac{2 \pi}{3}\right) & \sin \left(\theta-\frac{2 \pi}{3}\right) & 1 \\
\cos \left(\theta+\frac{2 \pi}{3}\right) & \sin \left(\theta+\frac{2 \pi}{3}\right) & 1
\end{array}\right]\left[\begin{array}{c}
V_{d} \\
V_{q} \\
V_{0}
\end{array}\right]
$$

\section{Configuration of Independent Vector Control of an Integrated Drive}

\subsection{CRETAM Technique}

The configuration of independent vector control scheme of an integrated dual PMSM under CRETAM technique is shown in Figure 8. It is very common to assume in this kind of system that $i_{d s}=0$, which keeps linearity between motor torque and current. The main traction motor and auxiliary compressor motor share the common fifth leg. Two speed controllers are employed both of which are PI types. The speed controller generates torque producing current component $i_{q s}$, which in turn is transformed into a, b, c frame, for the purpose of reference current generation.

It is seen from the above figure that both main and auxiliary PMSMs generate independent reference current signal. For CRETAM, current control current error is necessary, which is the difference of reference and sensed current. The current error which is generated by the difference of reference and sensed current is compared with triangular waveform and necessary switch in the leg is made to be turned on or off. By properly selecting hysteresis band, the hysteresis control can also be employed in the above scheme. At the driving two motors independently, the amplitude of the peak current flow in common leg is up to twice as others, so it is necessary to equip the power switching devices of common leg to double the capacity compared to others.

\subsection{SVPWM Technique}

The configuration of independent vector control scheme of an integrated dual PMSM under SVPWM technique is shown in Figure 9. The system configuration, with two PMSM drives is supplied with individual SVPWM. There are instants within the switching period when both machines simultaneously receive their active vectors of the FLI which corresponds to the active vectors 110 and 010 of the two machines, respectively, since inverter legs $A_{1}$ and $B_{1}$ supply phases $\mathrm{A}$ and $\mathrm{B}$ of the second machine while phases $\mathrm{C}$ are paralleled to the inverter leg $\mathrm{C}$. Thus the individual SV references of each machine are complementary and the modulator is able to simultaneously satisfy the needs of both motors.

It is also visible that in the remaining instants the individual SV references of each machine are conflicting and so the needs of one machine are met, whereas the second machine receives zero SV (111 or 000). It means 


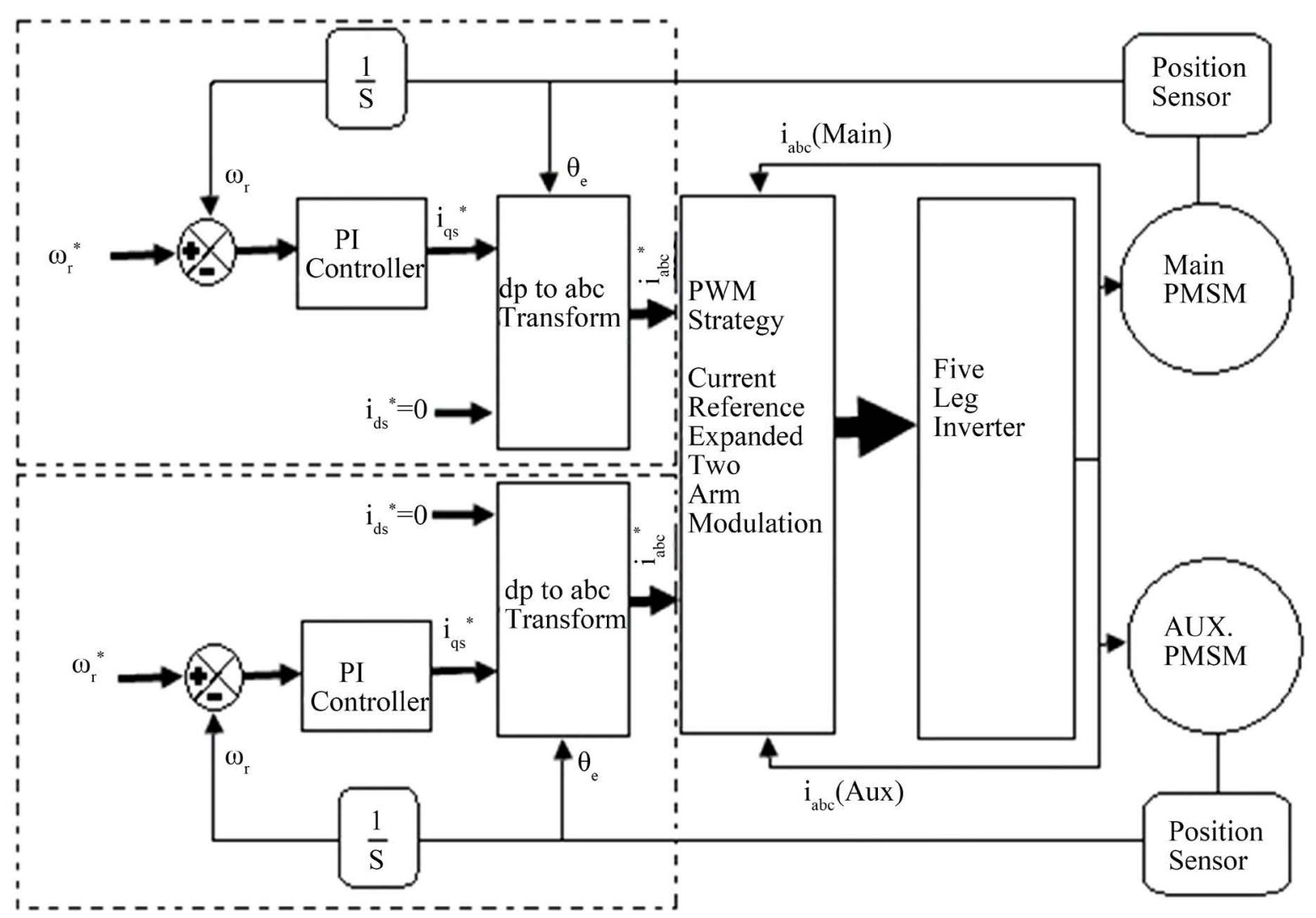

Figure 8. Independent vector control of main and auxiliary PMSMs under CRETAM technique.

that all $2^{5}=32$ switching states of a FLI are utilized and there are no restrictions regarding the use of any of them. The resulting PWM pattern is symmetrical with two commutations per inverter leg. It is seen that both main and auxiliary motors' have separate control signals which lead to an independent vector control.

\section{Simulation Results}

The configuration of independent vector control of main PMSM and auxiliary PMSM are simulated using the Matlab/Simulink/Sim Power system environment. The simulation is carried out such that parameter of main PMSM (PMSM_01) and auxiliary PMSM (PMSM_02) is same as shown in Table 1 . The dynamic response of PMSM_01 and PMSM_02under CRETAM technique running independently with different speed commands and load torques is shown from Figures 10-13. The PMSM_01 and PMSM_02 are set to run at 50\% of rated speed $(1500 \mathrm{rpm})$ and $25 \%$ of rated speed $(750 \mathrm{rpm})$ respectively, with load torque of half the rated load $0.4 \mathrm{Nm}$ and full load $(0.8 \mathrm{Nm})$ respectively. Also the step load torque commands to the PMSM_01 (0.2 Nm to 0.4 Nm) and PMSM_02 from $(0.3 \mathrm{Nm}$ to $0.6 \mathrm{Nm})$ are given at $0.24 \mathrm{~s}$ and $0.26 \mathrm{~s}$. Figures 14 (a)-(f) show the line to line voltages, phase voltages and stator current $f$ integrated PMSM drive with FLI in adopting CRETAM technique. It is evident that from the Figure 14, as the reference speed of PMSM_01 and PMSM_02 are different, the operating frequency of line to line and phase voltages are also different. Hence through a single solid state converter (FLI), it is possible to generate line and phase voltages at two different frequencies simultaneously.

The dynamic response of PMSM_01 and PMSM_02 under SVPWM technique running independently with different speed commands and load torques is shown from Figures 15-18. Exactly similar operating points and the perturbations are induced like CRETAM. Figures 19(a)-(d) shows the line to line voltages and phase voltages of integrated PMSM drive in FLI while adopting SVPWM technique.

In adopting CRETAM method, there is a considerable decrease in torque ripple compared to SVPWM method as shown in Figure 20(a) \& Figure 20(b). The torque response of main PMSM running at rated load (0.8 Nm) in SVPWM technique is subjected to a torque ripple of $0.3 \mathrm{Nm}$, whereas in the case of CRETAM approach there 


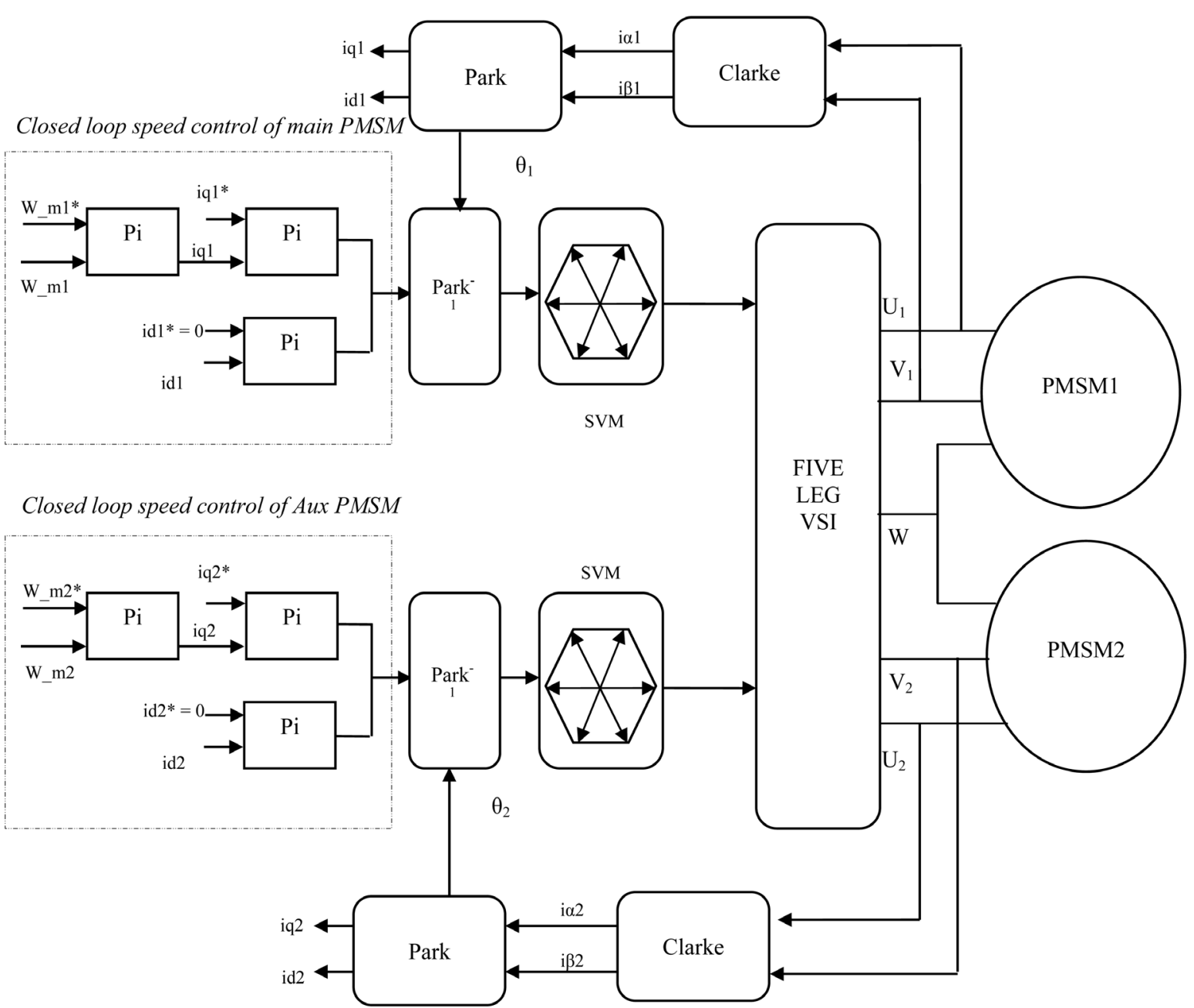

Figure 9. Independent vector control of main and auxiliary PMSMs under SVPWM technique.

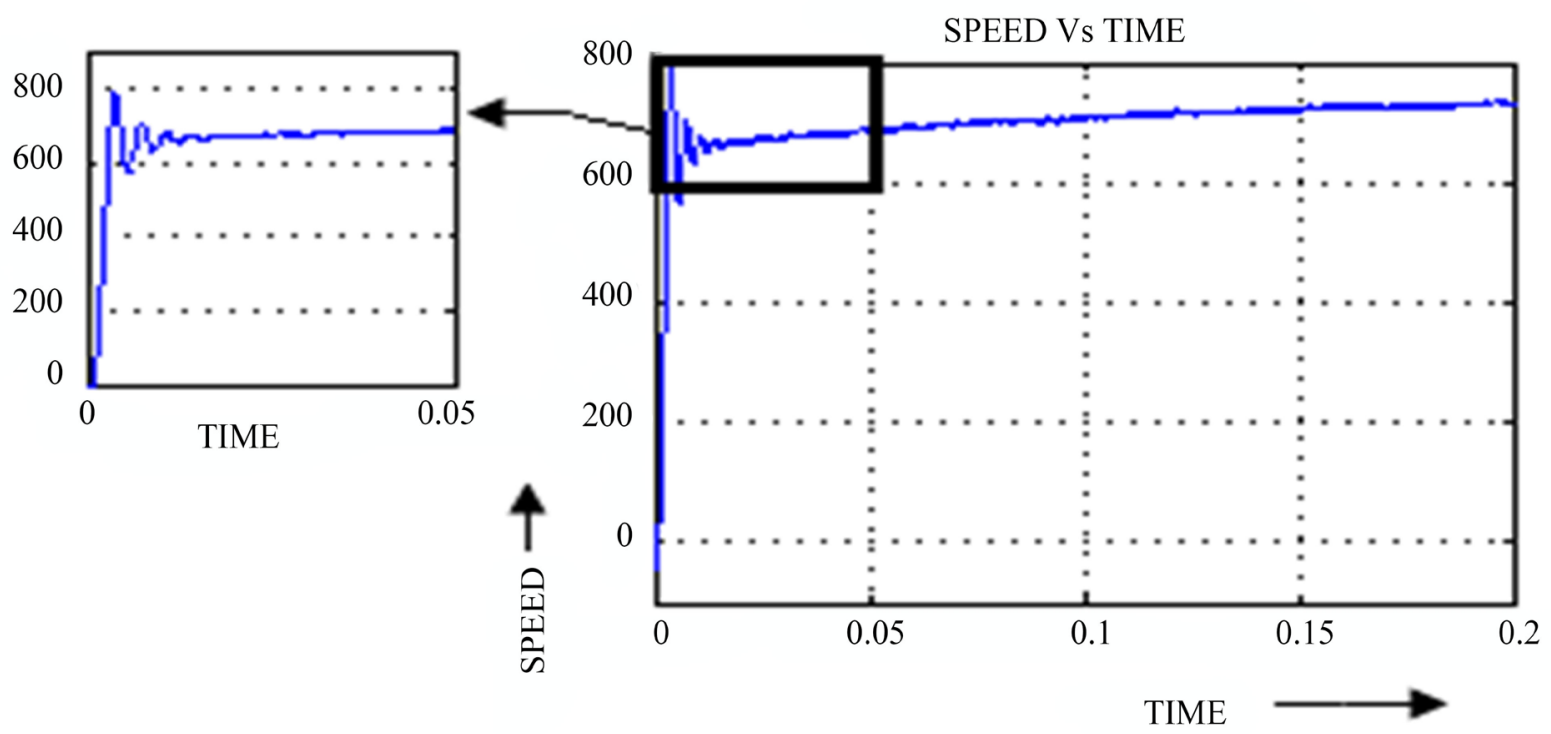

Figure 10. Speed response of PMSM_01-CRETAM. 


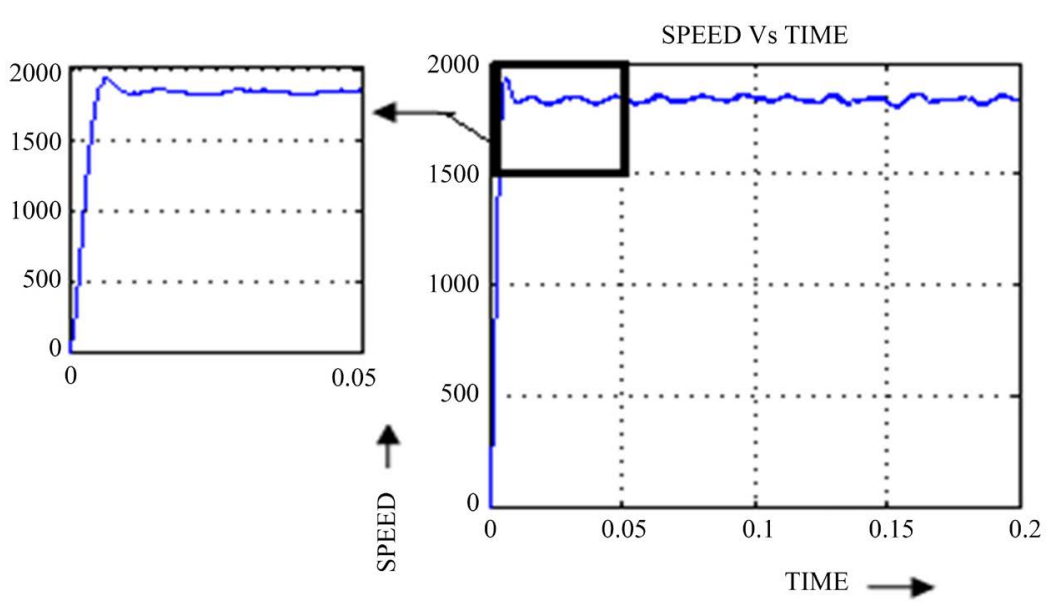

Figure 11. Speed response of PMSM_02-CRETAM.

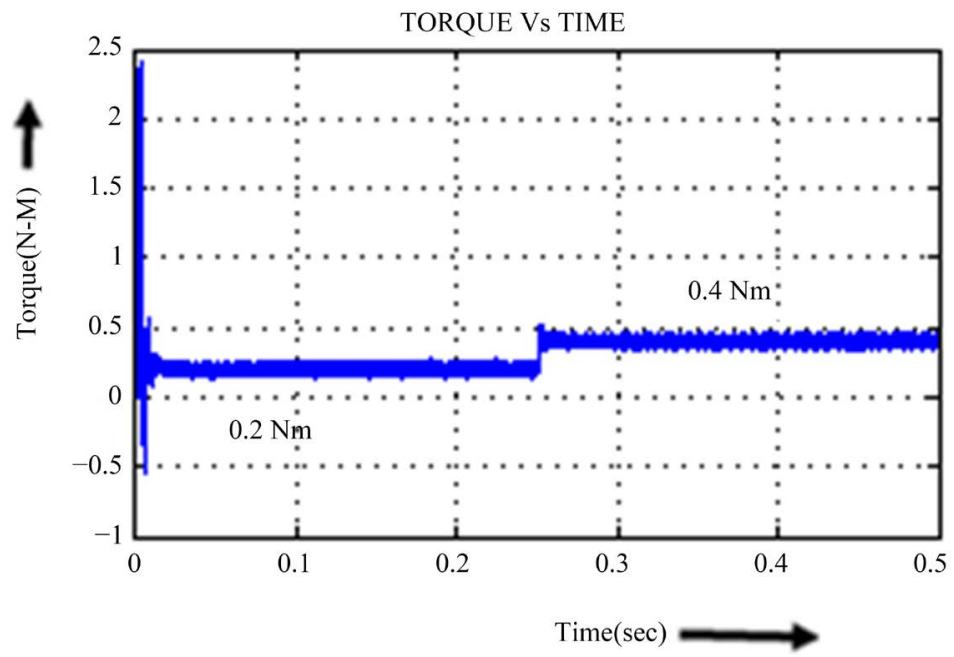

Figure 12. Torque response of PMSM_01-CRETAM.

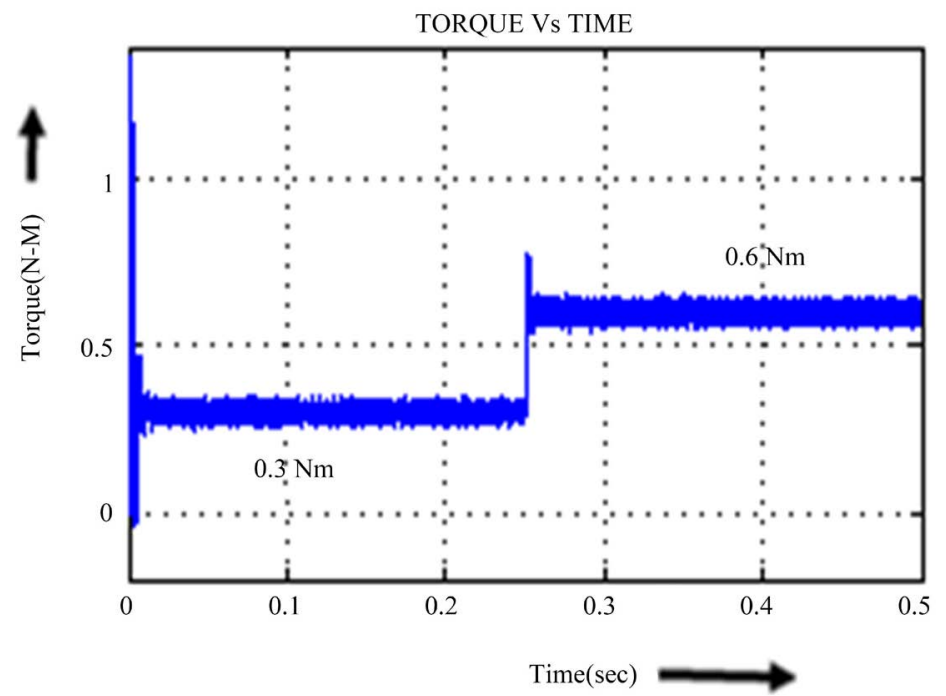

Figure 13. Torque response of PMSM_02-CRETAM. 


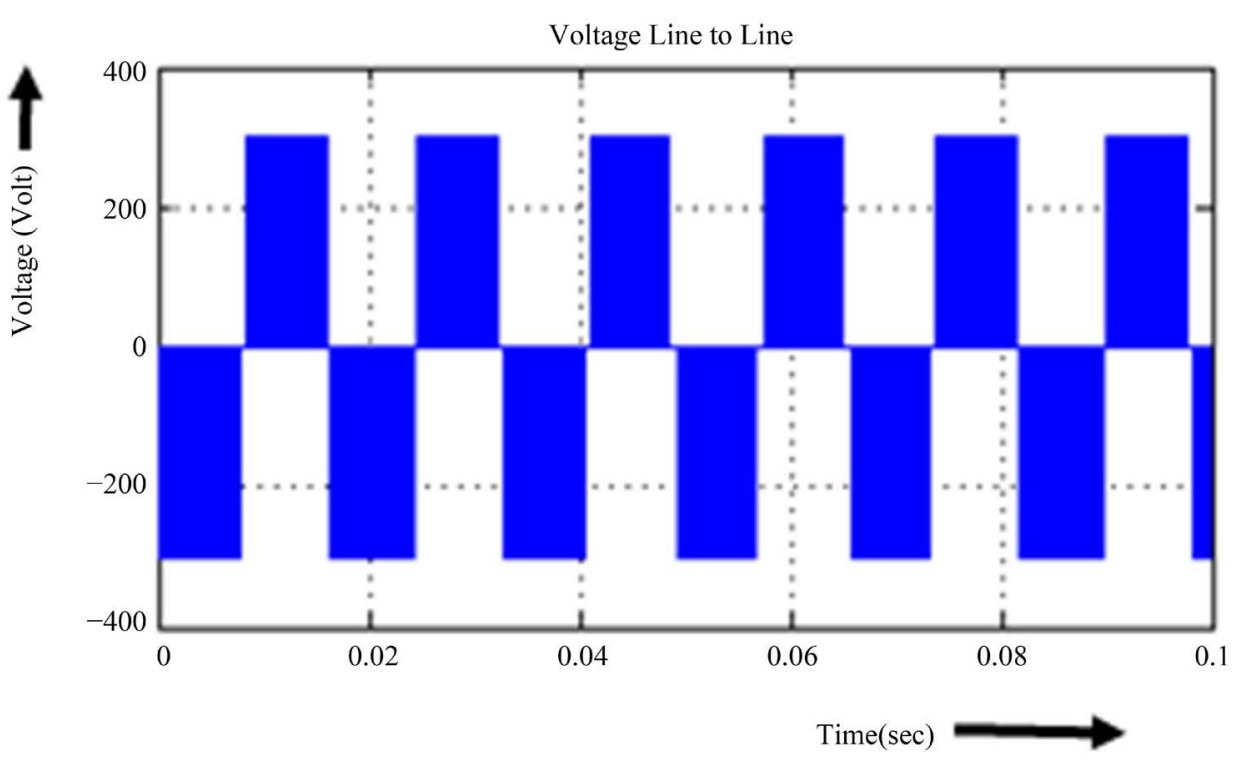

(a)

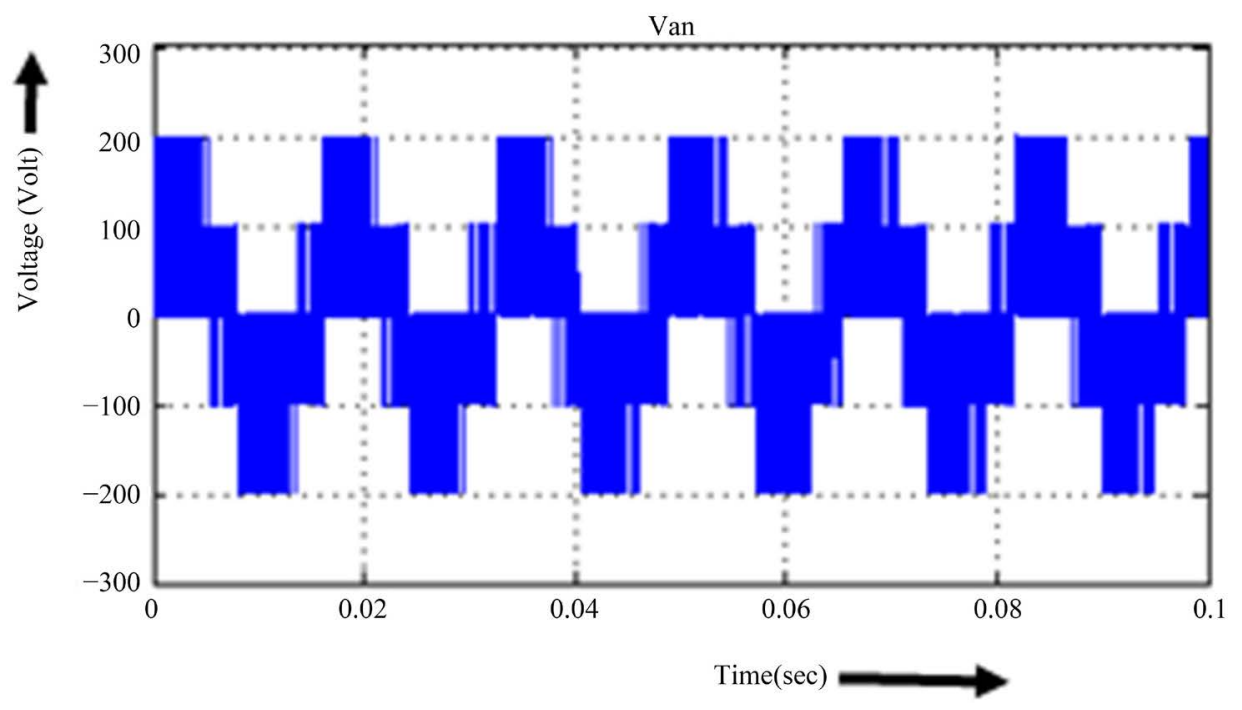

(b)

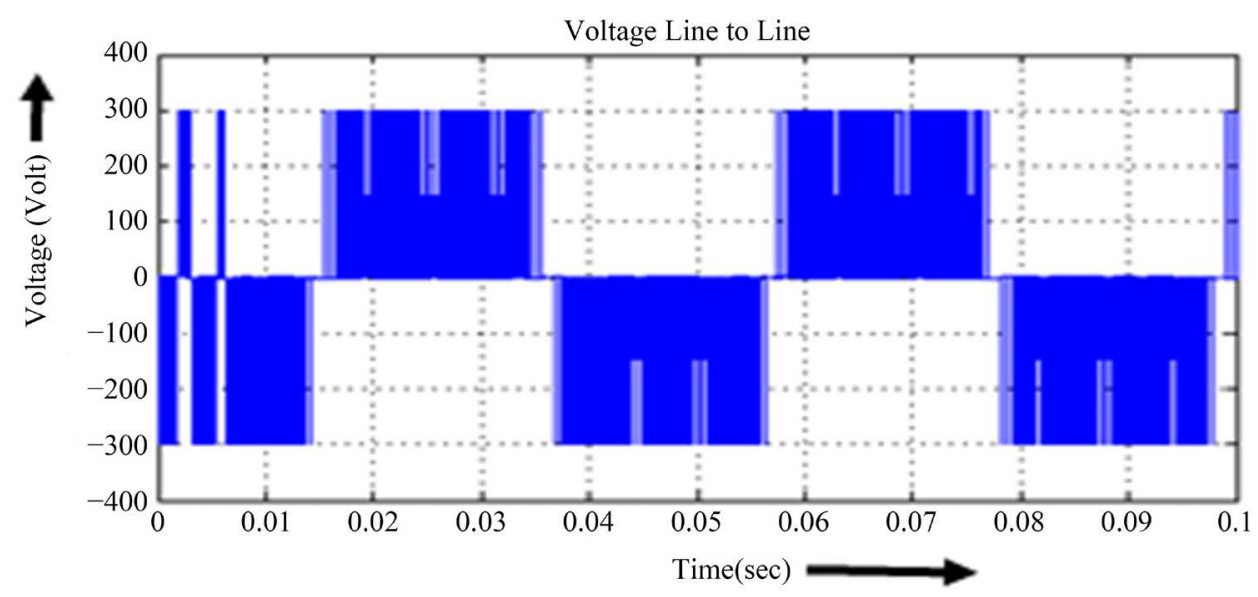

(c) 


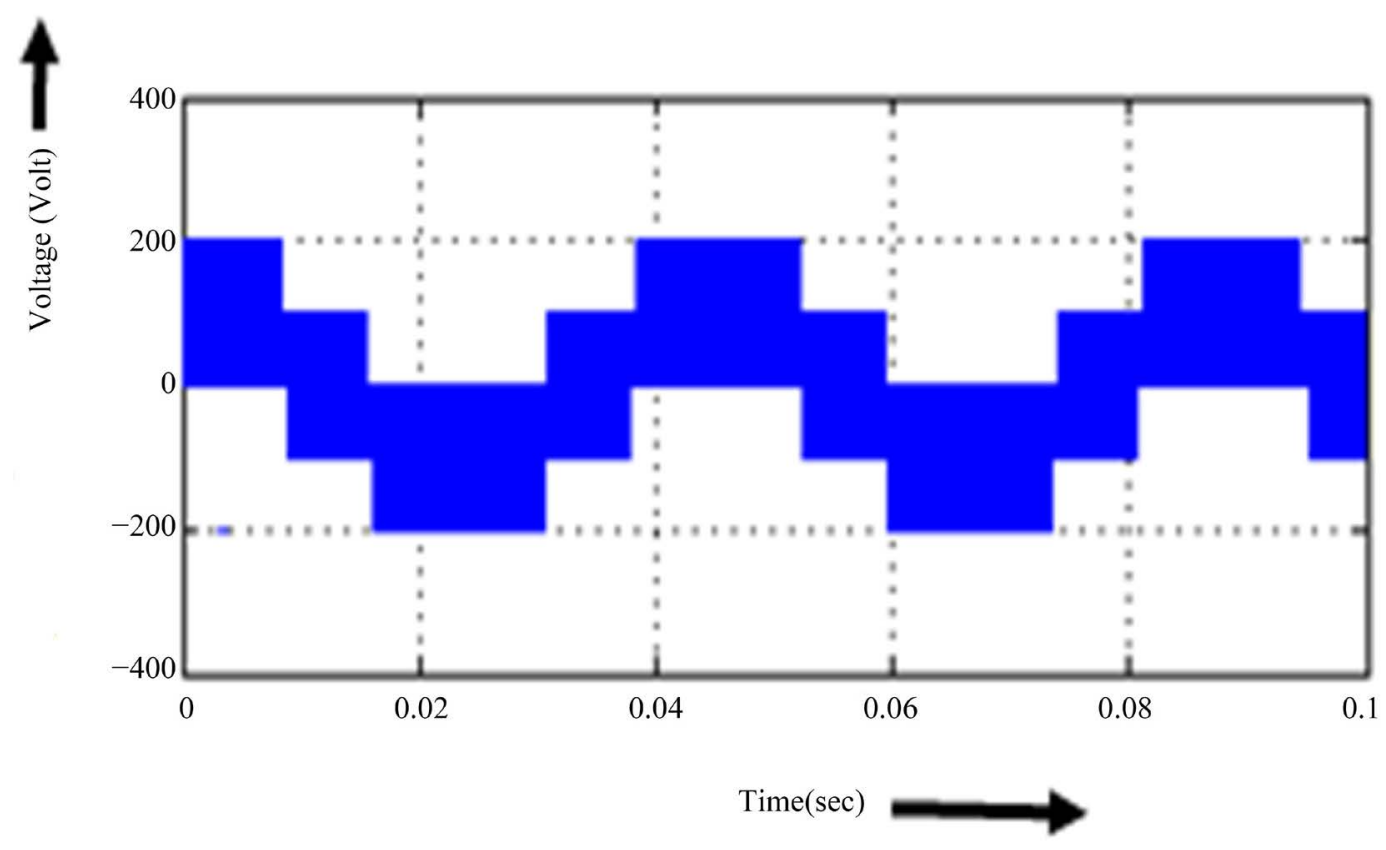

(d)

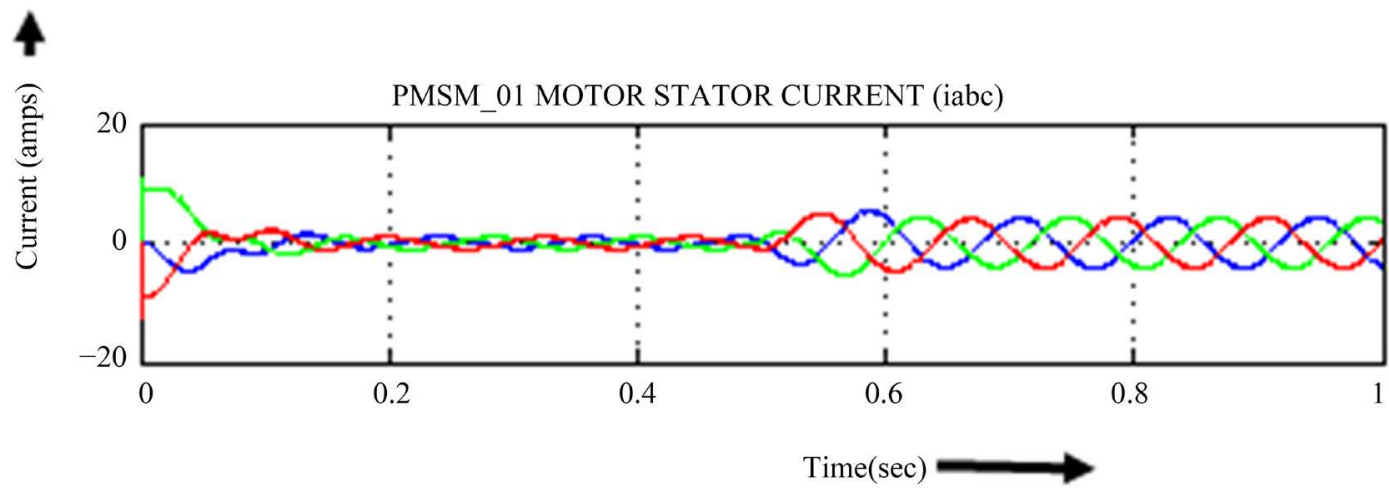

(e)

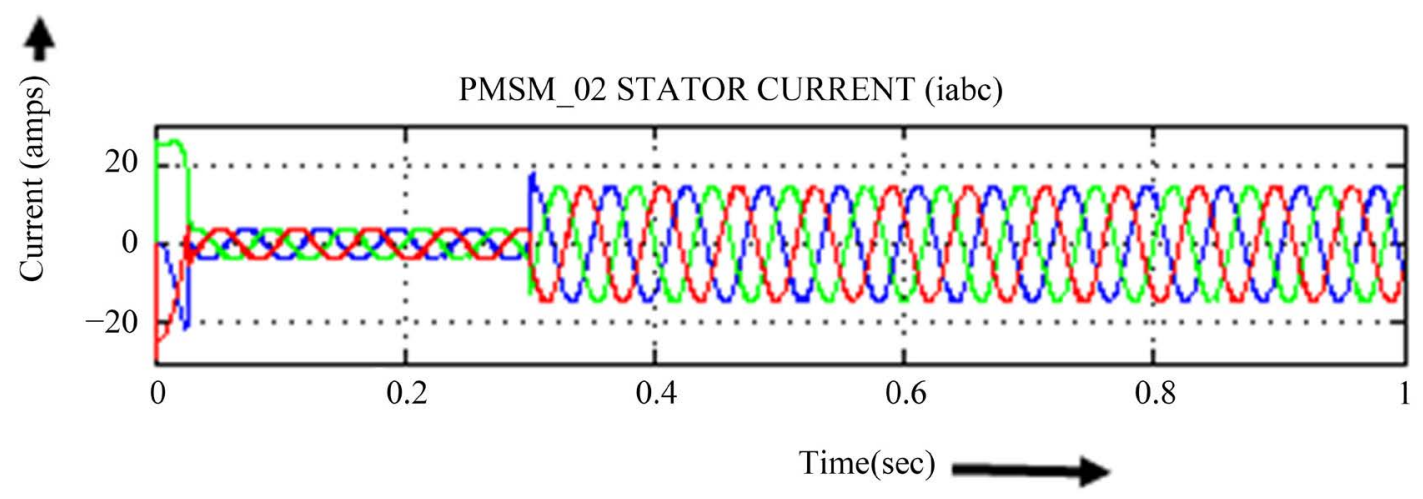

(f)

Figure 14. Simulation results of line to line voltage, phase voltage \& stator current of integrated Main \& Auxiliary PMSM drive in Five Leg VSI in adopting CRETAM technique. (a) Simulation result of line to line voltage of Main PMSM-FLI-CRETAM. (b) Simulation result of phase voltage of Main PMSM-FLI-CRETAM. (c) Simulation result of Line to Line voltage of PMSMD. (d) Simulation result of phase voltage of PMSM Auxiliary PMSM-FLI-CRETAM Auxiliary PMSM-FLI-CRETAM. (e) Simulation result of Stator Current of Main PMSMFLI-CRETAMF. (f) Simulation result of Stator Current of Main PMSM-FLI-CRETAM. 


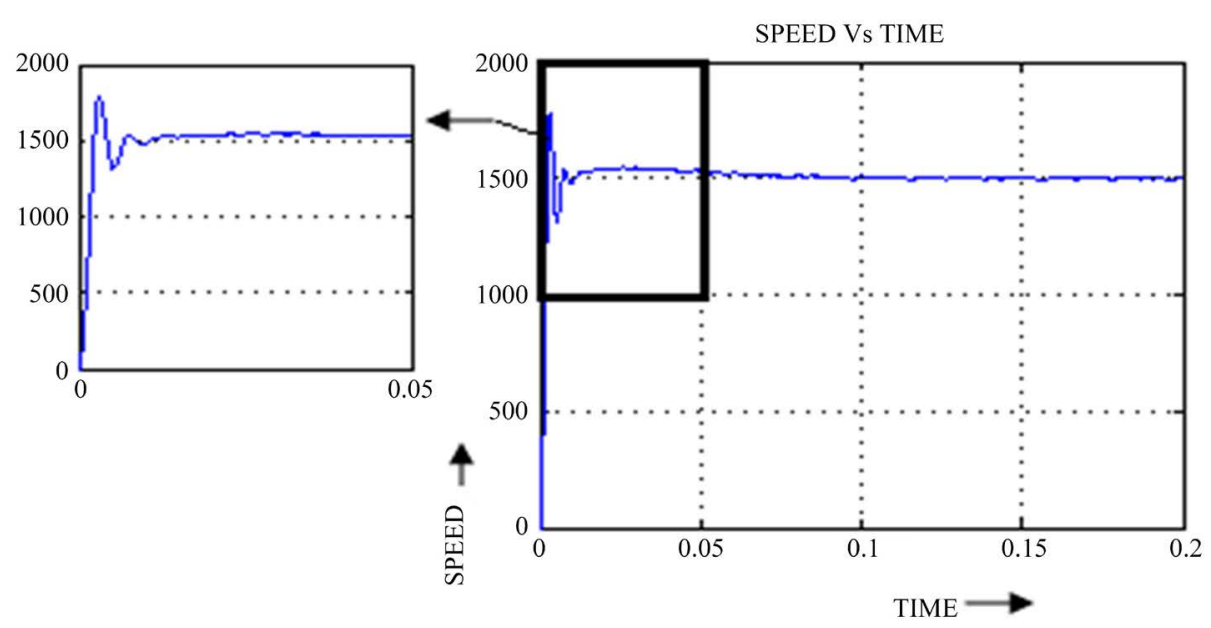

Figure 15. Speed response of PMSM_01 under SVPWM technique.

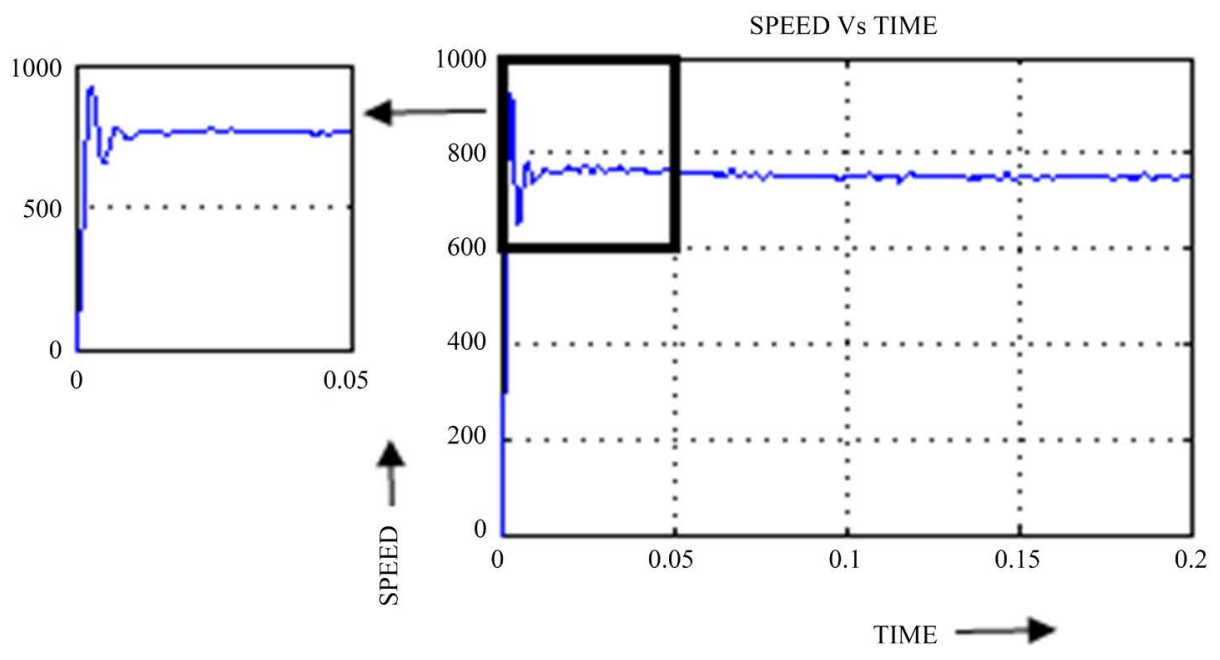

Figure 16. Speed response of PMSM_02 under SVPWM technique.

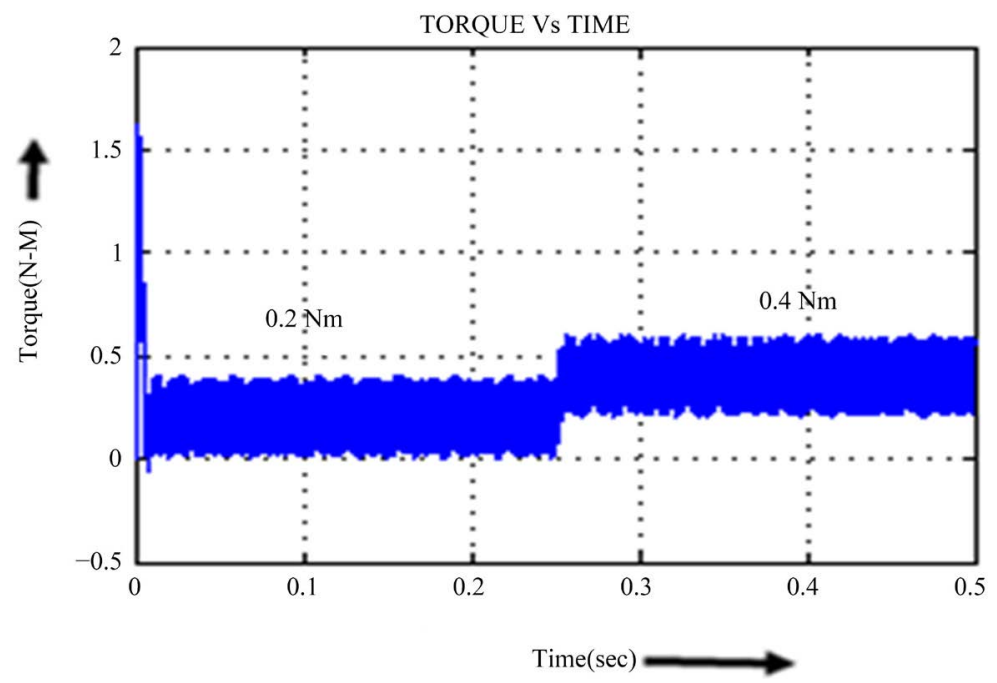

Figure 17. Torque response of PMSM_01 under SVPWM technique. 


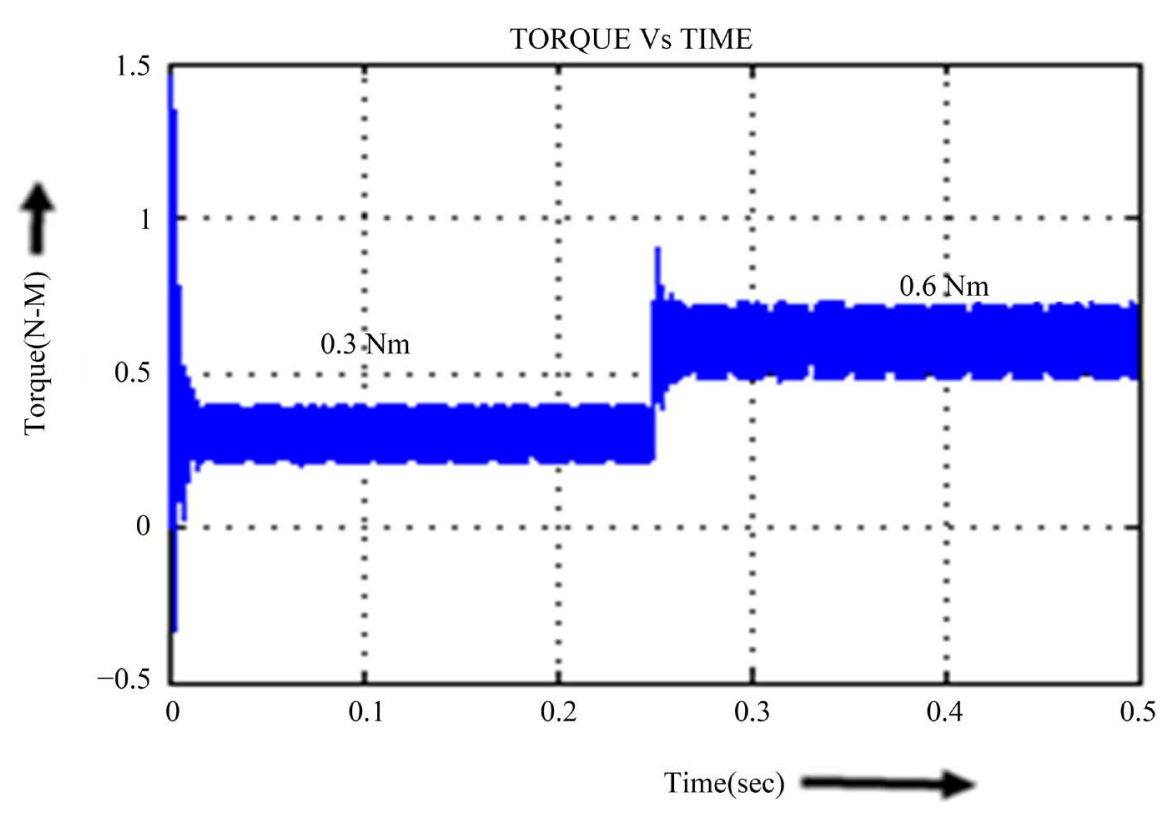

Figure 18. Torque response of PMSM_02 under SVPWM technique.

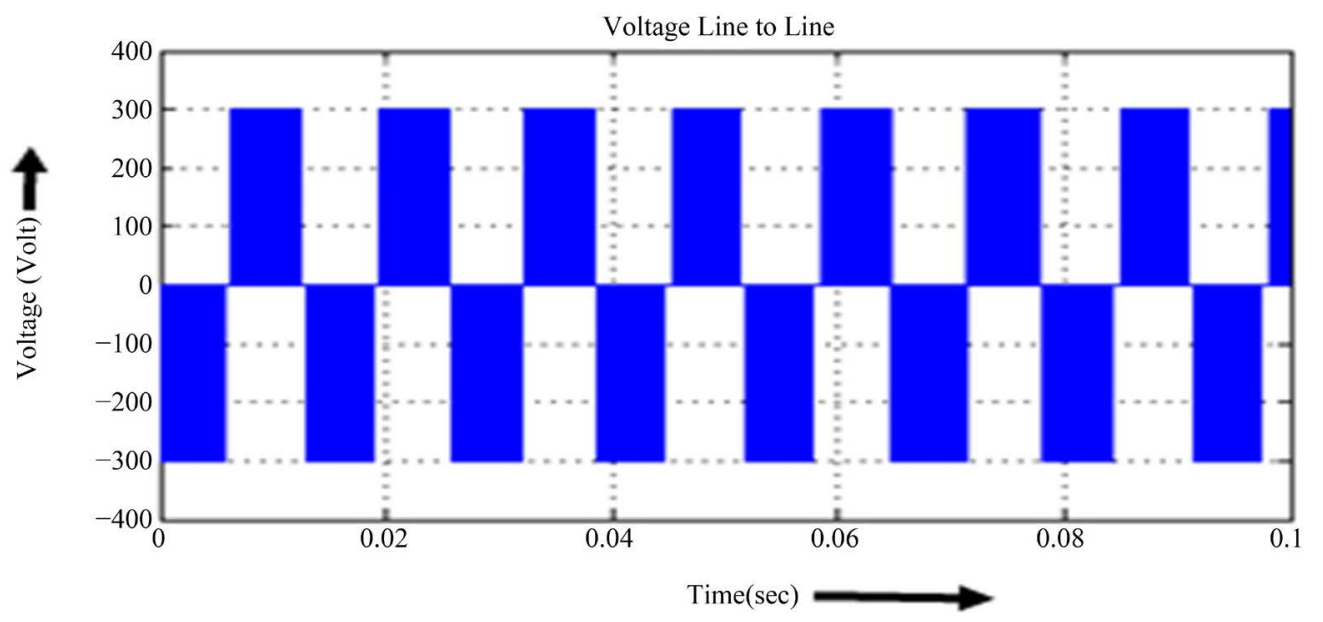

(a)

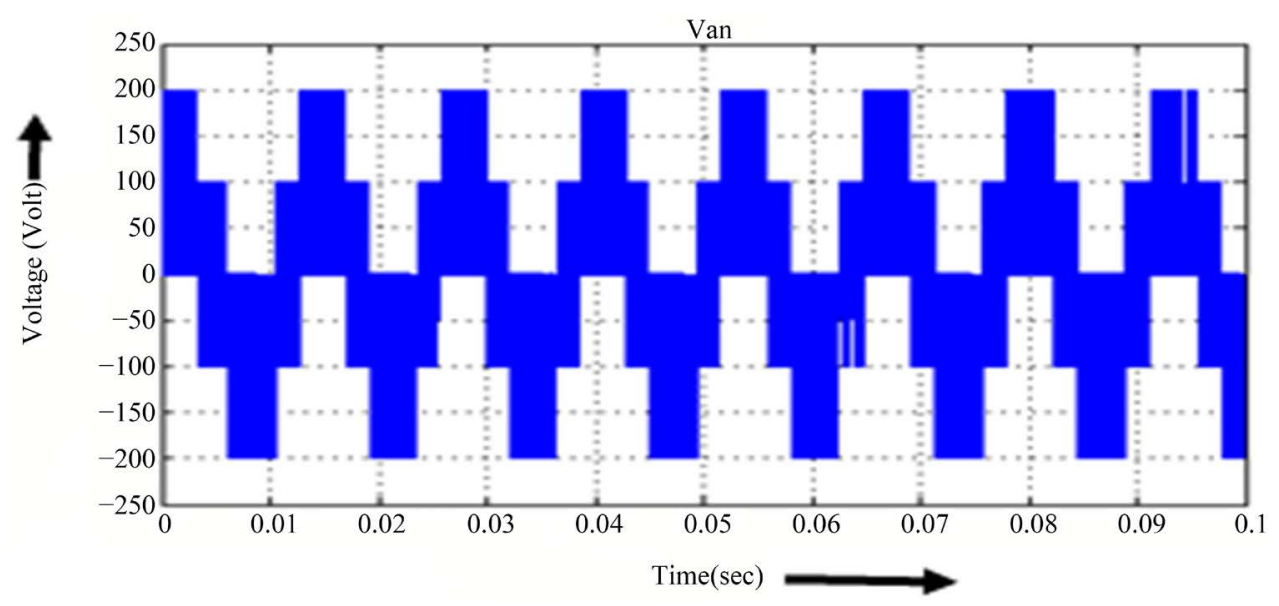

(b) 


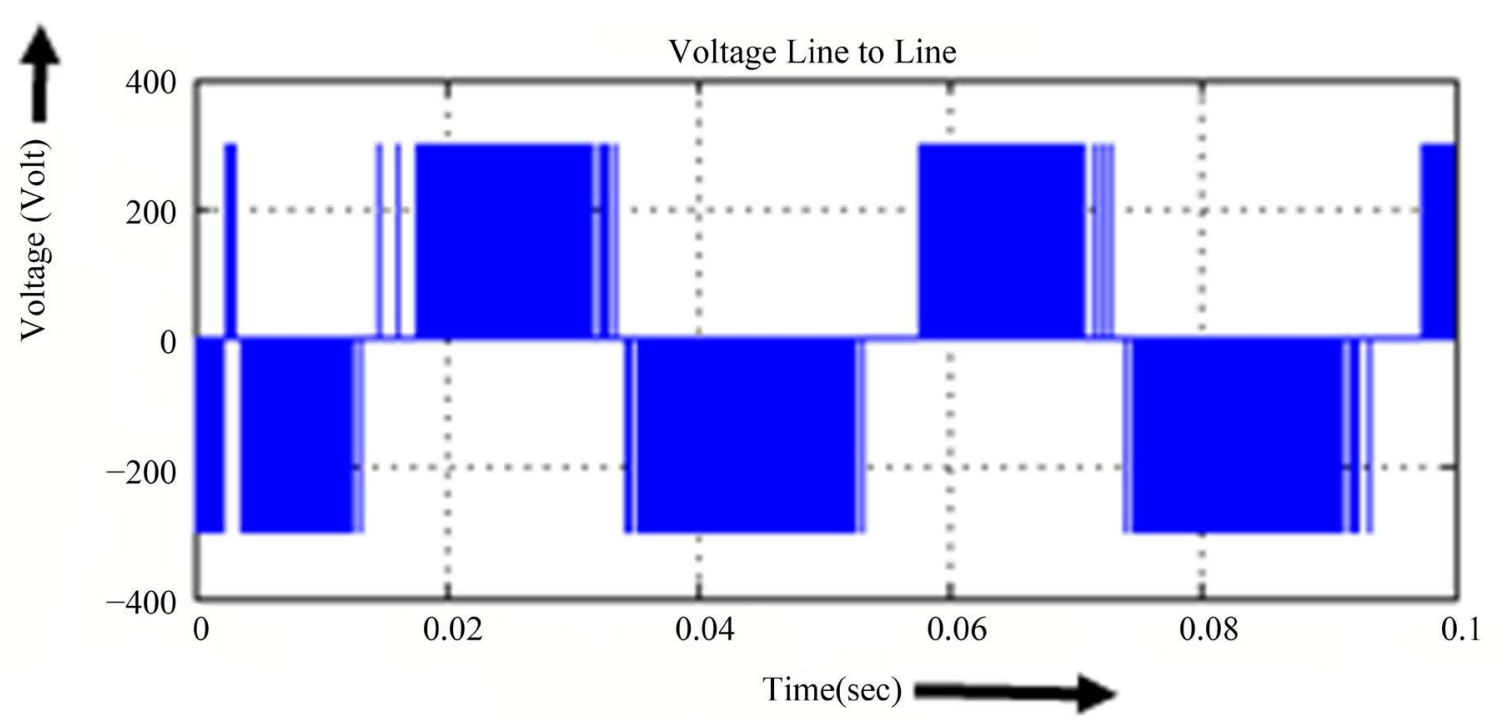

(c)

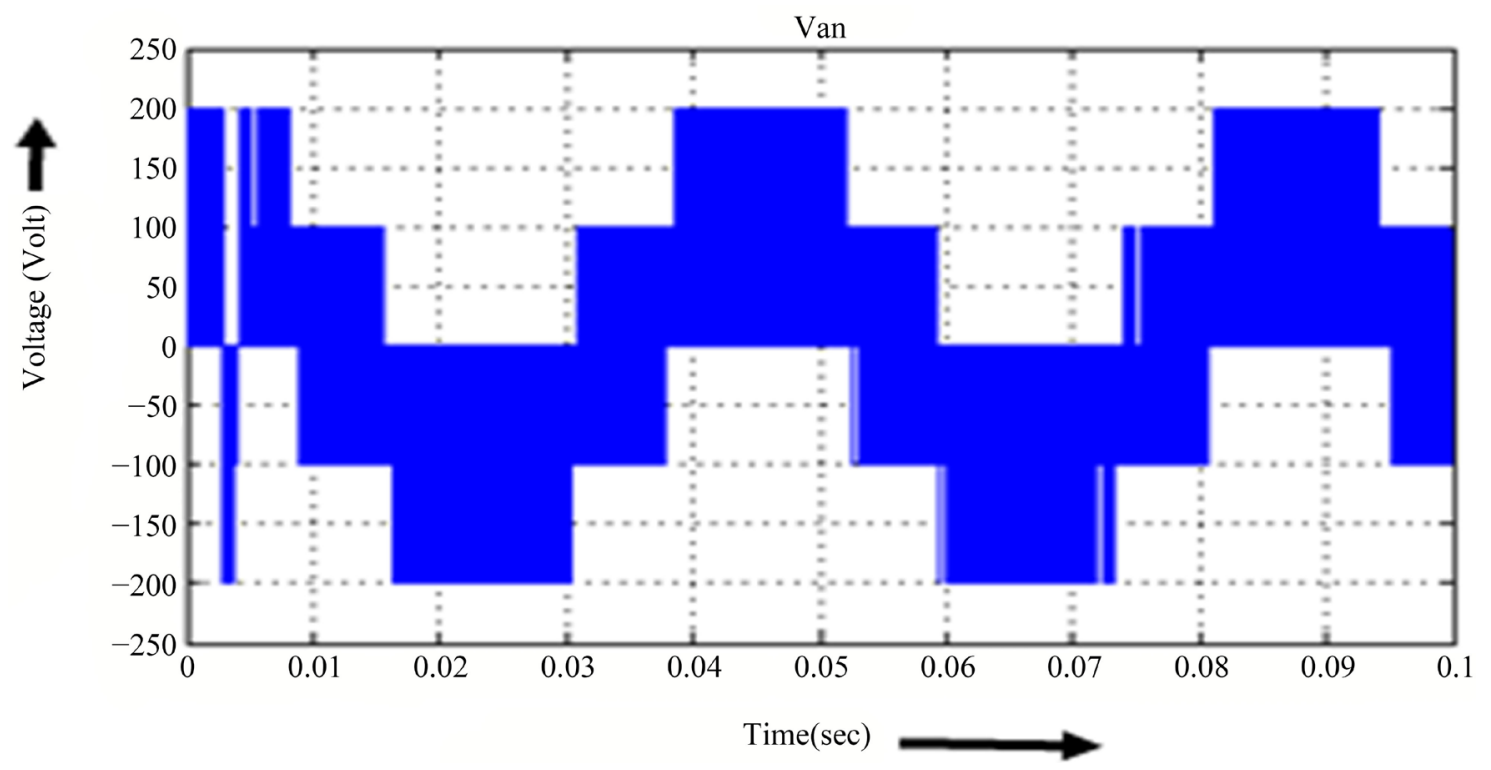

(d)

Figure 19. Simulation results of line to line voltage \& phase voltage of integrated Main \& Auxiliary PMSM drive in Five Leg VSI in adopting SVPWM technique. (a) Simulation result of line to line voltage of Main PMSM-FLI-SVPWMB. (b) Simulation result of phase voltage of Main PMSM-FLI-SVPWM. (c) Simulation result of Line to Line voltage of PMSMD. (d) Simulation result of phase voltage of PMSM Auxiliary PMSM-FLI-SVPWMPMSM-FLI-SVPWM.

is considerable reduction in torque ripple $(0.07 \mathrm{Nm})$ at same load. The main reason for reduction in torque ripple in CRETAM approach is mainly due to improved THD in comparison with SVPWM. As an illustration from Figures 20(c)-(h) the harmonic current spectrum at two different modulation techniques CRETAM and SVPWM are shown, i.e. THD is $9.89 \%$ for SVPWM and THD is $4.05 \%$ for CRETAM. The harmonic spectra of line to line voltage are also shown.

There is a considerable increase in DC bus voltage utilization in CRETAM in comparison with SVPWM.

Table 2 shows relative performance of voltage utilization at different values of modulation index in CRETAM and SVPWM techniques. On observing Table 2, the voltage utilization in CRETAM technique is satisfactory in comparison with SVPWM technique. Table 3 shows the value of stator current THD for PMSM1 and PMSM2. 


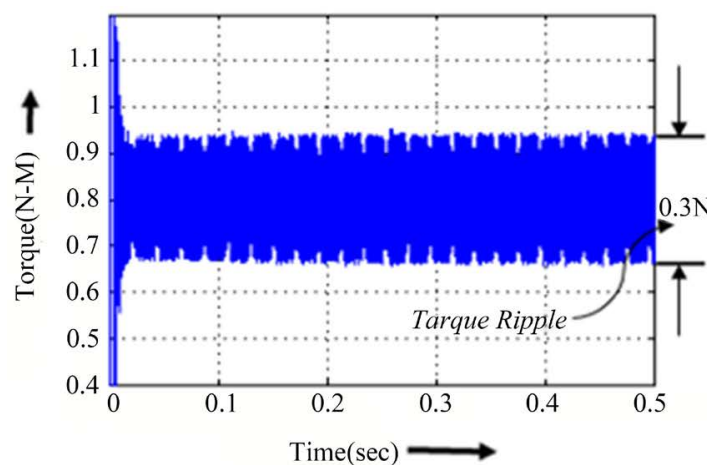

(a)

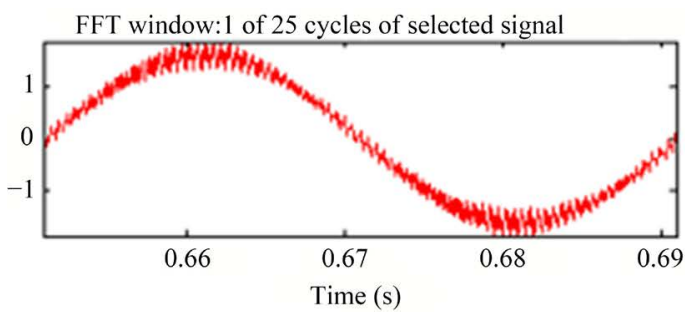

FFT analysis

(c)

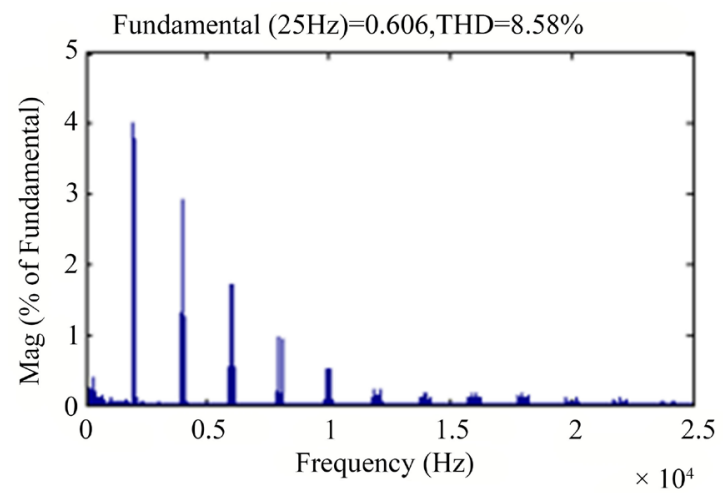

(e)

Fundamental $(50 \mathrm{~Hz})=106.7, \mathrm{THD}=14.48 \%$

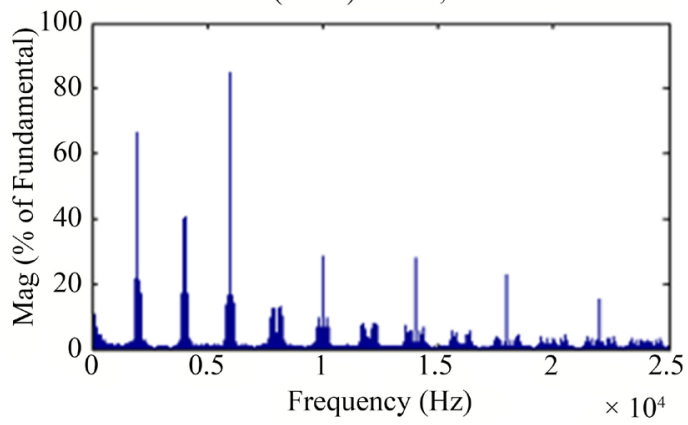

(g)

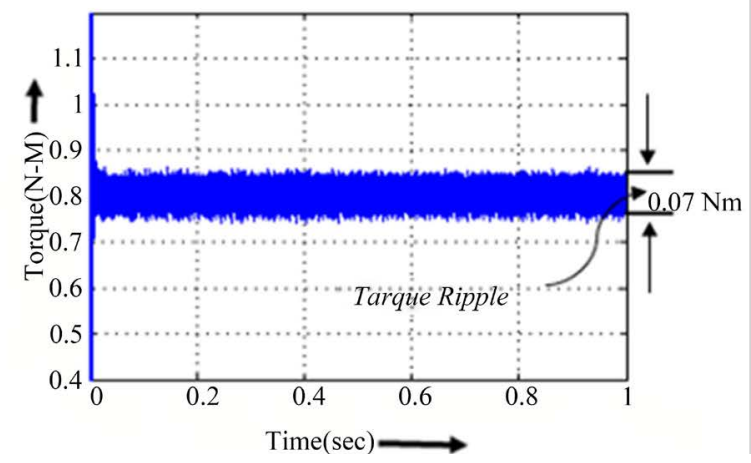

(b)

FFT window: 1 of 25 cycles of selected signal

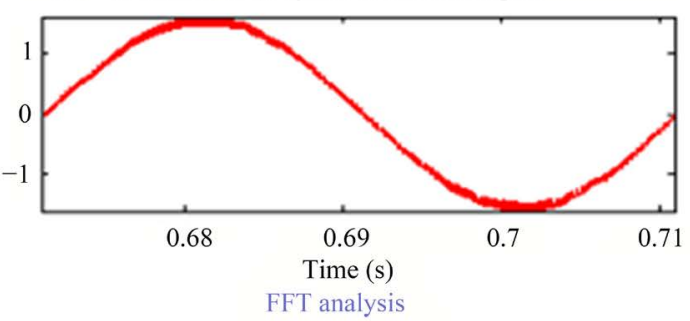

(d)

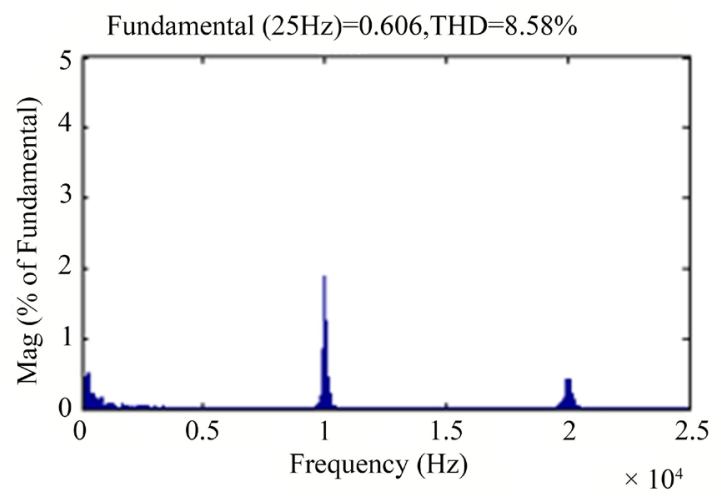

(f)

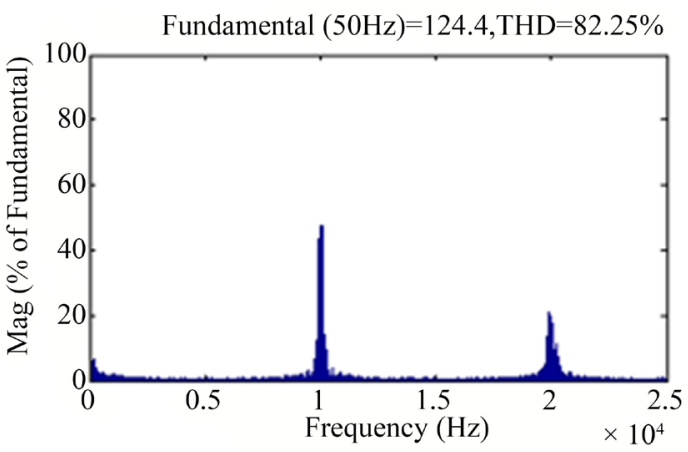

(h)

Figure 20. Various Performance Measures of Main \& Auxiliary PMSM drive in Five Leg VSI in Comparing the CRETAM and SVPWM technique. (a) \& (b) Torque response aux PMSM under SVPWM and CRETAM techniques respectively. (c) \& (d) Aux PMSM current under SVPWM and CRETAM technique respectively. (e) \& (f) Harmonic Spectrum of current with SVPWM and CRETAM technique respectively. (g) \& (h) Harmonic Spectrum of line voltage of Main PMSM with SVPWM and CRETAM technique respectively. 
Table 1. PMSM drive parameters for simulation.

\begin{tabular}{ccc}
\hline Parameters & PMSM_01 & PMSM_02 \\
\hline Rated output power $(\mathrm{kW})$ & 0.25 & 1.65 \\
Rated speed $(\mathrm{rpm})$ & 3000 & 2000 \\
Back EMF constant $\left(\mathrm{V}_{\mathrm{L}-\mathrm{L} \text { peak }} / \mathrm{krpm}\right)$ & 62.2859 & 62.28 \\
No of Poles & 4 & 8 \\
Rated Torque $(\mathrm{Nm})$ & 0.8 & 8 \\
Stator Resistance $(\Omega)$ & 18.7 & 0.9585 \\
Stator d and q axis inductance $(\mathrm{H})$ & 0.02682 & 0.00525 \\
Inertia $\left(\mathrm{Kg} \cdot \mathrm{m}^{2}\right)$ & $2.26 \mathrm{e}-5$ & 0.0006329 \\
Friction Factor $(\mathrm{Nm} \cdot \mathrm{s})$ & $1.349 \mathrm{e}-5$ & 0.0003035 \\
Flux Linkage & 0.171 & 0.1827 \\
\hline
\end{tabular}

Table 2. Relative performance of CRETAM \& SVPWM technique.

\begin{tabular}{|c|c|c|c|c|}
\hline \multirow{2}{*}{$\begin{array}{l}\text { PWM Techniques } \\
\text { Modulation Index }\end{array}$} & \multicolumn{2}{|c|}{ CRETAM } & \multicolumn{2}{|c|}{ SVPWM } \\
\hline & $\begin{array}{l}\mathrm{V}_{\text {line_RMS }} \text { (V) } \\
\text { (V) }\end{array}$ & $\begin{array}{l}\mathrm{V}_{\text {phase_RMS }} \text { RMS } \\
(\overline{\mathrm{V}})\end{array}$ & $\begin{array}{l}\mathrm{V}_{\text {line_RMS }} \mathrm{RMS} \\
(\mathrm{V})\end{array}$ & $\begin{array}{c}\mathrm{V}_{\text {phase_RMS }} \text { RMS } \\
(\bar{V})\end{array}$ \\
\hline 1 & 168.3 & 97.39 & 171.5 & 100.53 \\
\hline 0.8 & 152.3 & 87.86 & 157 & 90.58 \\
\hline 0.6 & 133.3 & 76.96 & 138.1 & 79.66 \\
\hline 0.4 & 111.5 & 64.47 & 115.8 & 66.51 \\
\hline 0.2 & 84.56 & 48.54 & 87.19 & 50.35 \\
\hline
\end{tabular}

Table 3. Current THD value PMSM1 and PMSM2 for varying input voltage.

\begin{tabular}{ccc}
\hline \multirow{2}{*}{ Input Voltage } & PMSM1 & PMSM2 \\
\cline { 2 - 3 } & Current THD (\%) & Current THD (\%) \\
200 & 24.77 & 19.16 \\
250 & 31.19 & 9.23 \\
300 & 41.23 & 10.34 \\
350 & 43.03 & 12.78 \\
\hline
\end{tabular}

\section{Conclusion}

A novel independent vector control of an integrated PMSM drive is proposed which can be extended to automotive application to control main traction PMSM and auxiliary HVAC compressor PMSM. The control algorithm for driving two Three-phase-PMSMs is achieved. A modified PWM method for FLI i.e. CRETAM technique has been adopted and tested in MATLAB/simulink. The simulation result reveals that, main and auxiliary PMSM motors can be independently controlled with different speed and torque commands even though the parameters for main and traction motor are different and it also clarifies the adopting of ETAM technique for independent control of traction and HVAC drive suffers from poor voltage utilization, increased THD and objectionable torque ripple.

\section{References}

[1] Su, G.-J. and Hsu, J.S. (2005) An Integrated Traction and Compressor Drive System for EV/HEV Applications. Pro- 
ceedings of the IEEE International Conference on Applied Power Electronics Conference and Exposition (APEC'05), 2, 719-725.

[2] Bose, B.K. (1986) Power Electronics and AC Drives. Chap. 2, Prentice-Hall, Upper Saddle River, 86-94.

[3] Dubey, G.K. (1989) Fundamentals of Electric Drives. Prentice-Hall, Upper Saddle River.

[4] Krishnan, R. (2001) Electric Motor Drives Modeling, Analysis and Control. Prentice- Hall, Upper Saddle River.

[5] Krishnan, R. (2010) Permanent Magnet Synchronous and Brushless DC Motor Drives. CRC Press, Boca Raton.

[6] Pillay, P. and Krishnan, R. (1988) Modeling of Permanent Magnet Motor Drives. IEEE Transactions on Industrial Electronics, 35, 537-541. http://dx.doi.org/10.1109/41.9176

[7] Pillay, P. and Krishnan, R. (1989) Modeling, Simulation and Analysis of Permanent-Magnet Motor Drives. Part 1: The Permanent-Magnet Synchronous Motor Drive. IEEE Transactions on Industry Applications, 25, 265-273. http://dx.doi.org/10.1109/28.25541

[8] Jacobina, C.B., da Silva, O.I., dos Santos Jr., E.C. and Lima, A.M.N. (2005) Reduced Switch Count Multi-Motor Drive Systems. Proceedings of the IEEE International Conference on Electric Machines and Drives (EMD'05), San Antonio, 15 May 2005, 1858-1862.

[9] Ledzema, E., McGrath, B., Munoz, A. and Lipo, T.A. (2001) Dual AC-Drive System with a Reduced Switch Count. IEEE Transactions on Industry Applications, 37, 1325-1333. http://dx.doi.org/10.1109/28.952508

[10] Delarue, P., Bouscayrol, A. and Semail, E. (2003) Generic Control Method of Multileg Voltage-Source-Inverter for Fast Practical Application. IEEE Transactions on Power Electronics, 18, 517-526. http://dx.doi.org/10.1109/TPEL.2003.809349

[11] Levi, E., Jones, M., Vukosavic, S.N. and Toliyat, H.A. (2004) A Novel Concept of a Multiphase, Multi-Motor Vector Controlled Drive System Supplied from a Single Voltage Source Inverter. IEEE Transactions on Power Electronics, 19, 320-335. http://dx.doi.org/10.1109/TPEL.2003.823241

[12] Su, G.-J. and Hsu, J.S. (2006) A Five Leg Inverter for Driving a Traction Motor and a Compressor Drive. IEEE Transactions on Power Electronics, 21, 687-692. http://dx.doi.org/10.1109/TPEL.2006.872366

[13] Jones, M., Vukosavic, S.N., Levi, E. and Iqbal, A. (2005) A Six-Phase Series-Connected Two-Motor Drive with Decoupled Dynamic Control. IEEE Transactions on Industry Applications, 41, 1056-1066. http://dx.doi.org/10.1109/TIA.2005.851020

[14] Jacobina, C.B., da Silva, O.I., dos Santos Jr., E.C. and Lima, A.M.N. (2005) Dual AC Drives with Five Leg Converter. Proceedings of the IEEE International Conference on Power Electronics Specialist Conference (PESC'05), Recife, 16 June 2005, 1800-1806.

[15] Jacobina, C.B., da Silva, O.I., dos Santos Jr., E.C., Lima, A.M.N. and de Freitas, L.S. (2005) AC Drive Systems Using Five Leg Converter and Series-Connected Machines. Proceedings of the IEEE International Conference on Power Electronics Specialist Conference (PESC'05), Recife, 16 June 2005, 2429-2435.

[16] Levi, E., Jones, M. and Dujic, D. (2008) A Performance Comparison of PWM Techniques for Five-Leg VSIs Supplying Two-Motor Drives. Proceedings of the IEEE International Conference on Industrial Electronics (IECON'08), Orlando, 10-13 November 2008, 508-513.

[17] Nozawa, Y., Oka, K., Omata, R. and Matsuse, K. (2006) Performance for Position Control of Two Permanent Magnet Synchronous Motors with the Five-Leg Inverter. Proceedings of the 32nd Annual Conference on IEEE Industrial Electronics (IECON'06), Paris, 6-10 November 2006, 1182-1187. http://dx.doi.org/10.1109/iecon.2006.347933

[18] Oka, K., Nozawa, Y. and Matsuse, K. (2006) An Improved Method of Voltage Utility Factor for PWM Control of a Five-Leg Inverter in Two Induction Motor Drives. IEEJ Transactions on Electrical and Electronic Engineering, 1, 108-111. http://dx.doi.org/10.1002/tee.20024

[19] Hara, A., Tanaka, T. and Matsuse, K. (2011) Position and Speed Controls of Two Permanent Magnet Synchronous Motors Fed by a Five-Leg Inverter. Proceeding of the IEEE International Conference on Power Electronics and ECCE Asia (ICPE \& ECCE'11), Jeju, 30 May-3 June 2011, 2478-2485.

[20] Hizume, M., Oka, K. and Hiroyuki, E. (2010) Independent Position Controls of Two Permanent Magnet Synchronous Motors Fed by a Five-Leg Inverter. Proceedings of the IEEE International Conference on Industry Applications Society Annual Meeting (IAS'10), Houston, 3-7 October 2010, 1-6.

[21] Jones, M., Vukosavic, S.N., Dujic, D., Levi, E. and Wright, P. (2008) Five-Leg Inverter PWM Technique for Reduced Switch Count Two-Motor Constant Power Applications. IET Electric Power Applications, 2, 275-287. http://dx.doi.org/10.1049/iet-epa:20070497

[22] Jacobina, C.B., da Silva, O.I., dos Santos Jr., E.C. and Lima, A.M.N. (2010) Two Motors Drive System Topologies with Five-Leg Inverter. Proceeding of IEEE International Conference on Vehicle Power and Propulsion (VPPC'10), Lille, 1-3 September 2010, 1-6.

[23] Tang, L.X. and Su, G.-J. (2008) High-Performance Control of Two Three-Phase Permanent-Magnet Synchronous Ma- 
chines in an Integrated Drive for Automotive Applications. IEEE Transactions on Power Electronics, 23, 3047-3055. http://dx.doi.org/10.1109/TPEL.2008.2005374

[24] Hara, A., Enokijima, H. and Matsuse, K. (2011) Independent Vector Control of Two Induction Motors Fed by a Five-Leg Inverter with Space Vector Modulation. Proceedings of the IEEE International Conference on Industry Applications Society Annual Meeting (IAS'10), Houston, 9-13 October 2011, 1-8.

[25] Iqbal, A. and Khan, M.A. (2008) A Simple Approach to Space Vector PWM Signal Generation for a Five-Phase Voltage Source Inverter. Proceedings of the Annual IEEE International Conference on India Conference (INDICON'08), 2, 418-424.

Submit or recommend next manuscript to SCIRP and we will provide best service for you:

Accepting pre-submission inquiries through Email, Facebook, Linkedin, Twitter, etc A wide selection of journals (inclusive of 9 subjects, more than 200 journals)

Providing a 24-hour high-quality service

User-friendly online submission system

Fair and swift peer-review system

Efficient typesetting and proofreading procedure

Display of the result of downloads and visits, as well as the number of cited articles

Maximum dissemination of your research work

Submit your manuscript at: http://papersubmission.scirp.org/ 